Research Article

\title{
Estimating the Tensile Strength of Ultrahigh-Performance Fiber-Reinforced Concrete Beams
}

\author{
In-Hwan Yang $\mathbb{D}^{1}{ }^{1}$ Changbin Joh $\mathbb{D}^{2}{ }^{2}$ and The Quang Bui ${ }^{1}$ \\ ${ }^{1}$ Kunsan National University, Department of Civil Engineering, Kunsan, Jeonbuk 54150, Republic of Korea \\ ${ }^{2}$ Korea Institute of Civil Engineering and Building Technology, Structural Engineering Research Institute, Goyang, \\ Gyeonggi 10223, Republic of Korea \\ Correspondence should be addressed to In-Hwan Yang; ihyang@kunsan.ac.kr
}

Received 19 December 2018; Accepted 11 April 2019; Published 2 May 2019

Guest Editor: Kazunori Fujikake

Copyright (c) 2019 In-Hwan Yang et al. This is an open access article distributed under the Creative Commons Attribution License, which permits unrestricted use, distribution, and reproduction in any medium, provided the original work is properly cited.

\begin{abstract}
The tensile behavior of ultrahigh-performance fiber-reinforced concrete (UHPFRC) depends on the dispersion and orientation of steel fibers within the concrete matrix. The uneven dispersion of randomly oriented steel fibers in concrete may cause differences in the tensile behavior between material testing specimens and beams. Therefore, in this study, the tensile behavior was investigated by fitting the analysis result of the moment-curvature curve to the experimental result of a UHPFRC beam. To this end, three UHPFRC mixtures with different compressive strengths were fabricated to test the material properties and flexural behavior of UHPFRC beams. Both a single type of steel fiber and a combination of steel fiber types were used with volume fractions of $1.0 \%$ and $1.5 \%$, respectively, in the three mixtures. Based on the design recommendations, the material properties of UHPFRC were modeled. The results ultimately show that by fitting the analysis results to the experimental results of the moment-curvature curves, the tensile strength of UHPFRC beams can be reasonably estimated.
\end{abstract}

\section{Introduction}

Concrete is a brittle material with a low tensile strength; furthermore, increasing the compressive strength of concrete will increase its brittleness. The advent of ultrahighperformance fiber-reinforced concrete (UHPFRC) represents the outcome of continuous research to improve the performance of high-strength concrete under tension. Following the improvements in its mechanical properties, UHPFRC has become suitable for many applications requiring long spans, such as in stadia, bridges, and docks. Therefore, many researchers have conducted numerous studies to explore the tensile and flexural behaviors of UHPFRC [1-6]. For example, uniaxial tensile tests were performed by Boulay et al. [7] and Wile et al. [8] to investigate the tensile behavior of UHPFRC, while Su et al. [9] and Mertol et al. [10] conducted a series of bending beam tests to study the flexural behavior of UHPFRC. In addition, Li et al. [11] examined the influences of UHPFRC and high-strength reinforcement on the flexural behavior of reinforced concrete beams. The findings of these studies revealed that the use of UHPFRC increases the overall performance of a beam relative to the use of high-strength concrete.

The most important factor affecting the tensile behavior of UHPFRC is the inclusion of steel fiber. The addition of steel fiber to UHPFRC makes it more ductile, increases its strength, and improves its resistance to cracking [12-16]. The results of a study performed by Ren et al. [17] indicated that the flexural strength, load carrying capacity, energy absorption capacity, fracture toughness, and fracture energy increased significantly with increasing steel fiber content. Moreover, Yoo et al. [18] investigated the effects of four different fiber volume fractions on the mechanical and fracture properties of UHPFRC; their results showed that an increase in the fiber volume fraction increased the flexural strength of notched beams. Subsequently, to investigate the flexural behavior of steel fiber-reinforced concrete beams under both quasistatic and impact loads, Yoo et al. [19] used four different fiber volume contents ranging from $0 \%$ to 
$2.0 \%$ and concluded that the inclusion of a large quantity of steel fibers would enhance the flexural strength, deflection capacity, and toughness of the beams.

However, the orientation and distribution of steel fiber in a concrete matrix are random; unfortunately, this randomness can considerably affect the flexural response of a UHPFRC beam. Consequently, many researchers have attempted to control the orientation and distribution of steel fibers in UHPFRC members. For instance, Abrishambaf et al. [20] and Kang and Kim [21] quantified the effect of the fiber orientation on the tensile behavior of UHPFRC and concluded that the fiber orientation significantly affects the tensile behavior of UHPFRC, especially its deflection-hardening behavior. According to the studies of Yang et al. [22] and Kang and Kim [21], in which two different methods for emplacing concrete were adopted, steel fiber orientation is influenced by the method utilized to place UHPFRC. In addition, Al-Mattarneh [23] determined the concentration, dispersion, and orientation of steel fibers in concrete by using a surface electromagnetic sensor. Furthermore, Nunes et al. [24] estimated the tensile strength of thirty-six UHPFRC layers with varying fiber contents and fiber orientation distributions based on a comparison of magnetic measurements and experimental results.

Therefore, the objective of this study is to estimate the tensile behavior of UHPFRC beams subjected to flexure. The experimental parameters included the compressive strength of UHPFRC and the volume content of a combination of steel fibers. Target compressive strengths of 120, 150, and $180 \mathrm{MPa}$ were considered for the UHPFRC; moreover, both a single type of steel fiber and a combination of steel fiber types with volume fractions of $1.0 \%$ and $1.5 \%$, respectively, were used in this study. The material behavior of UHPFRC was modeled based on material testing results, and flexural tests were carried out on nine UHPFRC beams. Finally, the tensile strength of the UHPFRC beams was estimated by fitting the analysis results with the testing results of the moment-curvature curves.

\section{Material Properties of UHPFRC}

2.1. Mixing Proportions. In this study, the UHPFRC mixtures included straight steel fibers at volume fractions of $1.0 \%$ and $1.5 \%$. Ordinary Portland cement (OPC) was used as the cementitious material, and fine aggregate with a diameter of $0.5 \mathrm{~mm}$ or less was used. The water-binder ratios $(w / b)$ were 0.18 and 0.22 , and a polycarboxylic acid-based high-performance water-reducing agent with a density of 1.01 was used to ensure workability with a low water-binder ratio. In addition, filler and zirconium were also used in the UHPFRC mixtures.

Three fiber-reinforced concrete mixtures, namely, FRC120, FRC150, and FRC180, were fabricated, where the number in each mixture label represents the target compressive strength of the resultant concrete. A single type of straight fiber with a length of $19.5 \mathrm{~mm}$ was used in the FRC120 mixture at a volume fraction of $1.0 \%$, while a combination of fibers was utilized in the FRC150 and
FRC180 mixtures at a volume fraction of $1.5 \%$. The combination of fibers used in the FRC150 and FRC180 mixtures constituted $0.5 \%$ straight fibers with a length of $16.5 \mathrm{~mm}$ and $1.0 \%$ straight fibers with a length of $19.5 \mathrm{~mm}$. The straight fibers had a diameter of $0.2 \mathrm{~mm}$, a unit weight of $7500 \mathrm{~kg} / \mathrm{m}^{3}$, and a tensile strength of $2500 \mathrm{MPa}$. The detailed mixing proportions are given in Table 1.

2.2. Compressive Behavior of UHPFRC. The compressive strength of UHPFRC was obtained through compressive testing on cylindrical specimens with a height of $200 \mathrm{~mm}$ and a diameter of $100 \mathrm{~mm}$. Three linear variable displacement transducers (LVDTs) were installed around the cylindrical specimens to measure the displacement during the loading step. The stress-strain curve of the UHPFRC was calculated by using the load-displacement relationship, which was obtained from the compressive strength test. In addition, the modulus of elasticity was calculated from the UHPFRC stress-strain curve [25].

The mean compressive strengths of the FRC120, FRC150, and FRC180 specimens were 133.7, 148.8, and 181.2 $\mathrm{MPa}$, respectively. In addition, the mean elastic moduli of the FRC120, FRC150, and FRC180 specimens were 40150, 43220 , and $45140 \mathrm{MPa}$, respectively.

2.3. Tensile Behavior of UHPFRC. To evaluate the tensile behavior of UHPFRC, including its postcracking behavior, prismatic specimens of each mixture were fabricated and tested. The prismatic specimens, which had a height of $100 \mathrm{~mm}$, a width of $100 \mathrm{~mm}$, and a length of $400 \mathrm{~mm}$, had a notch with a depth of $10 \mathrm{~mm}$ cut into the tensile zone. The crack mouth opening displacement (CMOD) was measured by using a clip gauge attached to both edges of the notch.

A three-point loading test was performed to obtain the tensile behavior of the UHPFRC. The clear span length between the specimen supports was $300 \mathrm{~mm}$, and the load was measured during its application. To measure the deflections of the prismatic specimens, three LVDTs were attached at the midheight of each specimen. The experimental setup for measuring the CMOD of the prismatic specimens is shown in Figure 1. The load-CMOD relationship curves of the FRC120, FRC150, and FRC180 specimens are shown in Figure 2.

2.4. Modeling the Material Properties of UHPFRC. The UHPFRC stress-strain relationship was modeled based on the current design recommendations [26]. Based on the compressive stress-strain test results of the cylindrical specimens, the compressive stress-strain relationship was modeled as a linear curve by using the maximum compressive strength and elastic modulus; a linear shape was chosen because the experimental results showed an approximately linear relationship between the compressive stress and strain.

The tensile behavior of the UHPFRC can be estimated by performing an inverse analysis based on the testing results of 
TABLE 1: Mixing proportions of the UHPFRC.

\begin{tabular}{|c|c|c|c|c|c|c|c|c|c|}
\hline \multirow{2}{*}{ Mixture } & \multirow{2}{*}{$w / b$} & \multirow{2}{*}{$W$} & \multicolumn{3}{|c|}{ Binders } & \multirow{2}{*}{$S$} & \multirow{2}{*}{$F$} & \multicolumn{2}{|l|}{ Steel fiber } \\
\hline & & & $\mathrm{OPC}$ & $\mathrm{Zr}$ & BFS & & & Fiber volume content, $V_{\mathrm{f}}(\%)$ & Diameter, $D_{\mathrm{f}}(\mathrm{mm})$ \\
\hline FRC120 & 0.22 & 209 & 770 & 58 & 135 & 847 & 231 & $1.0=1.0(19.5 \mathrm{~mm})$ & 0.2 \\
\hline FRC150 & 0.18 & 180 & 788 & 99 & 99 & 867 & 236 & $1.5=1.0(19.5 \mathrm{~mm})+1.0(16.5 \mathrm{~mm})$ & 0.2 \\
\hline FRC180 & 0.18 & 178 & 783 & 196 & - & 862 & 235 & $1.5=1.0(19.5 \mathrm{~mm})+1.0(16.5 \mathrm{~mm})$ & 0.2 \\
\hline
\end{tabular}

OPC: ordinary Portland cement; Zr: zirconium; BFS: blast-furnace slag; S: sand; F: filler; W: water.

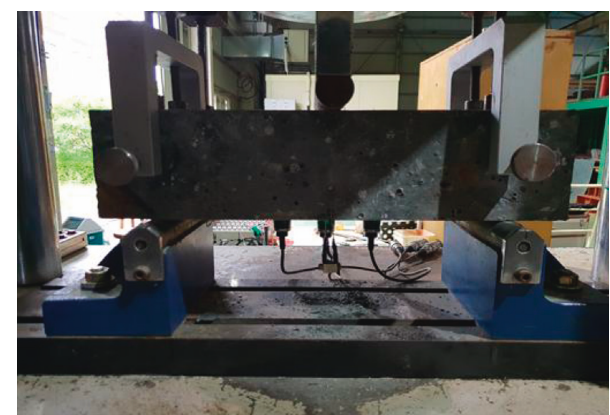

Figure 1: CMOD test setup.

the load-CMOD relationship curve. Accordingly, the tensile stress-CMOD relationship was derived from the loadCMOD relationship through inverse analysis, after which the tensile stress-strain curve was obtained from the tensile stress-CMOD relationship. The tensile strengths of the FRC120, FRC150, and FRC180 mixtures estimated from the load-CMOD relationship were $7.21,9.07$, and $7.76 \mathrm{MPa}$, respectively; these results show that the tensile strength of the FRC180 mixture was less than that of the FRC150 mixture. At the beginning of the test, it was expected that the tensile strength of UHPFRC would increase with the compressive strength; however, this is not consistent with the tensile test results. The tensile and compressive stressstrain relationships are shown in Figure 3. The equations for the characteristic points of the curve are as follows:

$$
\varepsilon_{\mathrm{el}}=\frac{f_{\mathrm{ctk}, \mathrm{el}}}{E_{\mathrm{cm}}}
$$

where $\varepsilon_{\text {el }}$ is the elastic tensile strain corresponding to the characteristic elastic tensile strength, $f_{\text {ctk,el }}$ is the characteristic elastic tensile strength, and $E_{\mathrm{cm}}$ is the mean elastic modulus of the UHPFRC.

$$
\begin{gathered}
\varepsilon_{\text {peak }}=\frac{w_{0.3}}{l_{\mathrm{c}}}+\frac{f_{\mathrm{ctk}, \mathrm{el}}}{E_{\mathrm{cm}}}, \\
\varepsilon_{1 \%}=\frac{w_{1 \%}}{l_{\mathrm{c}}}+\frac{f_{\mathrm{ctk}, \mathrm{el}}}{E_{\mathrm{cm}}} .
\end{gathered}
$$

where $\varepsilon_{\text {peak }}$ is the equivalent strain corresponding to the local peak in the postcracking phase or to a crack width equal to $0.3 \mathrm{~mm}$ if there is no peak, and $w_{0.3}$ represents the crack opening width corresponding to $0.3 \mathrm{~mm}$. $\varepsilon_{1 \%}$ is the equivalent strain corresponding to a crack width of $0.01 \mathrm{H}$; $w_{1 \%}=0.01 H$, where $H$ denotes the height of the prismatic specimen; and $l_{c}$ is the characteristic length expressed as $l_{c}=2 h / 3$, where $h$ is the depth of the cross section of the beam.

$$
\varepsilon_{\lim }=\frac{l_{\mathrm{f}}}{4 l_{\mathrm{c}}},
$$

where $\varepsilon_{\text {lim }}$ is the ultimate strain beyond which the effect of fiber is no longer taken into account in the ultimate limit state and $l_{\mathrm{f}}$ is the length of the steel fiber.

The compressive stress-strain relationships for the FRC120, FRC150, and FRC180 mixtures are shown in Figure 4, and those simulated for each mixture are represented by the solid lines in Figure 5 . The values of the characteristic points are listed in Table 2.

\section{Bending Test of UHPFRC Beams}

3.1. Bending Test Setup. A total of nine beams with rectangular cross-sectional dimensions of $200 \times 250 \mathrm{~mm}$ and a length of $3300 \mathrm{~mm}$ were fabricated and tested. Figure 6 shows the beam dimensions and reinforcement details. The main experimental variables of the test beams were the compressive strength of the concrete and the reinforcement ratio (i.e., rebar ratio) of the beams; these variables are listed in Table 3. Three different types of UHPFRC with compressive strengths of 120,150 , and $180 \mathrm{MPa}$ were cast with different rebar ratios, which ranged between 0.59 and $1.19 \%$. The constant moment region was $600 \mathrm{~mm}$ long; in this region, stirrups were not used while they were placed in the shear spans. All beams were reinforced by stirrups with a diameter of $10 \mathrm{~mm}$ at a spacing of $150 \mathrm{~mm}$ to avoid shear failure at both shear spans.

The beams were tested under a four-point loading system, as shown in Figure 7. The load was applied by a hydraulically operated actuator and a spread beam. A pair of steel supports was utilized with a support placed at either end of the beams separated by a clear span of $3000 \mathrm{~mm}$. The distance between the two loading points was $600 \mathrm{~mm}$, and the displacement control of the load was maintained at a rate of $1.5 \mathrm{~mm} / \mathrm{min}$.

Three LVDTs were placed within the constant moment region of each beam to measure the deflection during the test. To obtain the strain of both the concrete and the rebar, electrical resistance strain gauges were also attached to each beam. The strain in the concrete was measured by five strain gauges attached on the sides of the beams at the midspan, and the strain in the rebar was measured by four strain gauges attached on the surface of the rebar.

3.2. Bending Test Results. The cracking and failure patterns of the UHPFRC beams are shown in Figure 8. The beams began to crack initially in the constant moment region, and 


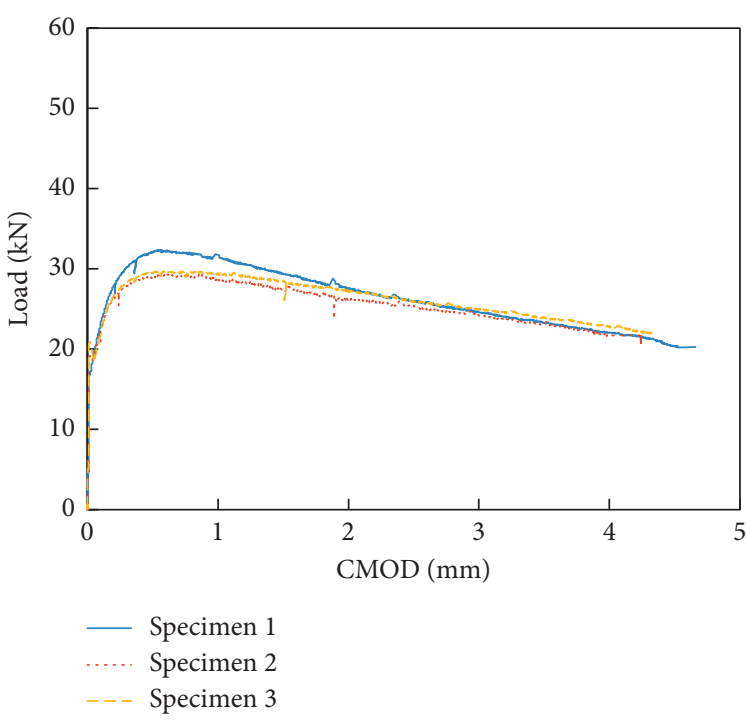

(a) FRC120 specimens

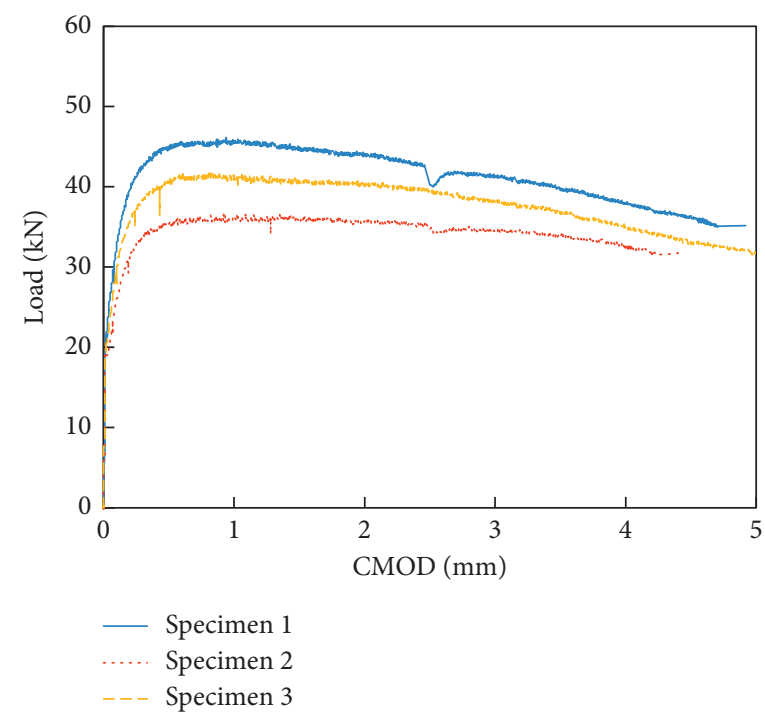

(b) FRC150 specimens

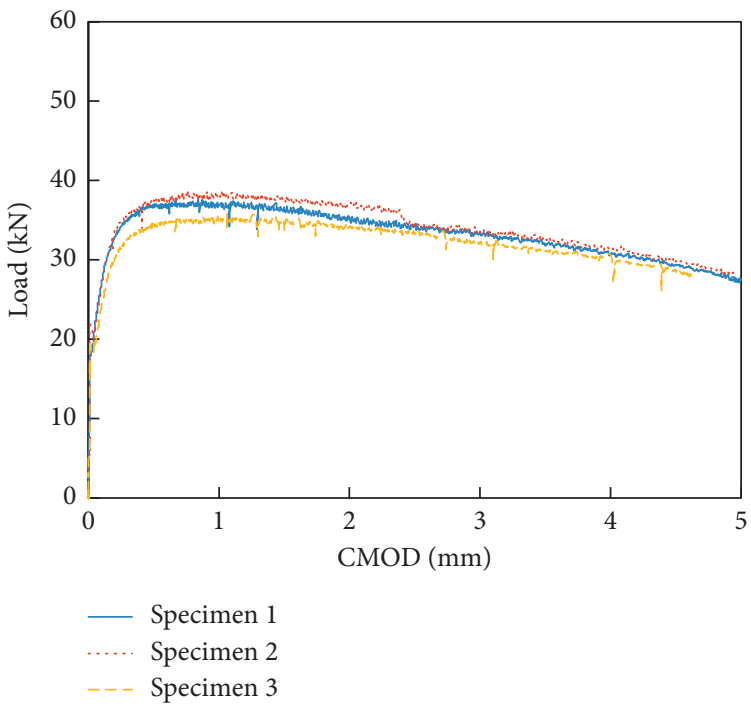

(c) FRC180 specimens

Figure 2: Load-CMOD relationship curves.

more cracks formed between the existing cracks as the load increased. The cracks were well distributed throughout the constant moment region at a low loading level, and more cracks formed in the shear spans at a higher loading level. After the peak load was reached, a single crack from the existing cracks within the constant moment region significantly widened and developed into a localized major crack, as shown in Figure 8. The localization of cracking within the constant moment region can cause bridging cracks to weaken and eventually form a plastic hinge. Moreover, the experimental results showed that steel fibers were pulled out of the matrix at the ultimate state.

The load-deflection curves of the beams with different rebar ratios are shown in Figure 9, and the bending test results of the beams are also shown in detail in Table 4. With regard to the beams with a rebar ratio of $0.59 \%$ (R2), the peak loads of the FRC120-R2, FRC150-R2, and FRC180-R2 beams were $66.7,76.0$, and $111.5 \mathrm{kN}$, respectively. The FRC180-R2 beam exhibited a greater peak load than the other beams. With regard to the beams with a rebar ratio of $0.89 \%$ (R3), the peak loads of the FRC120-R3, FRC150-R3, and FRC180-R3 beams were significantly different from each other. The highest peak load of $131.3 \mathrm{kN}$ was obtained for the FRC180-R3 beam, while the peak loads of the FRC120-R3 and FRC150-R3 beams were 123.3 and $118.6 \mathrm{kN}$, respectively. With regard to the beams with a rebar ratio of $1.19 \%$ (R4), the FRC180-R4 beam exhibited a peak load of $147.2 \mathrm{kN}$, which was greater than that of the other beams; the peak loads of the FRC120-R4 and FRC150-R4 beams were 127.3 and $139.9 \mathrm{kN}$, respectively. For each rebar ratio, the peak loads of the FRC180 beams were greater than those of the FRC120 and FRC150 beams. Therefore, the bending strength of UHPFRC beams is considerably affected by the compressive strength of the concrete. 


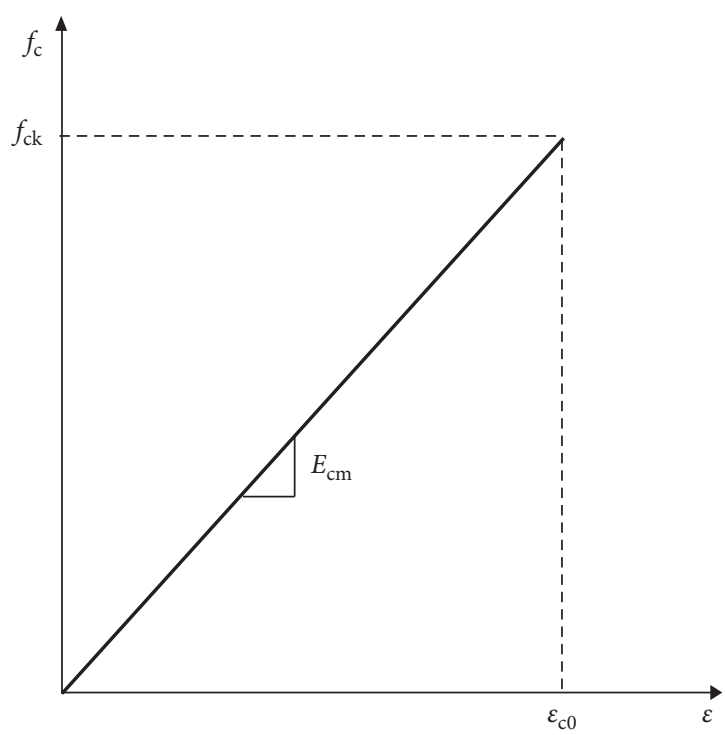

(a) Compression

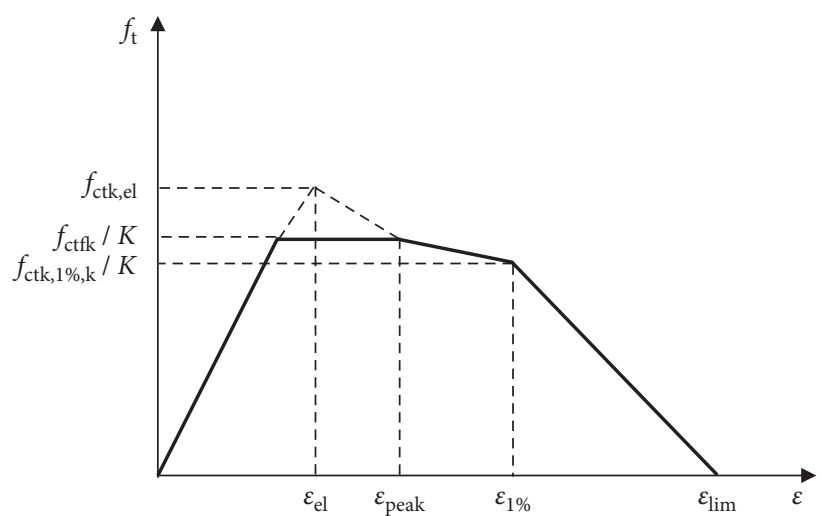

(b) Tension

FIgURE 3: Stress-strain relationships.

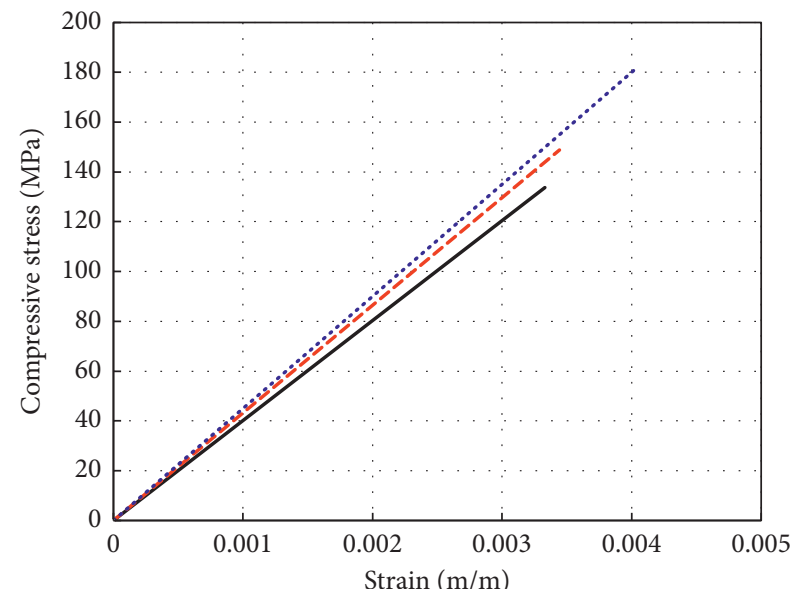

$\begin{array}{ll}\text { — } & \text { FRC120 } \\ \ldots-- & \text { FRC150 } \\ \ldots . . & \text { FRC180 }\end{array}$

FIGURE 4: Modeling of the compressive behavior of UHPFRC.

With regard to the beams with a rebar ratio of $0.59 \%$ (R2), the deflections at the ultimate states of the FRC120-R2, FRC150-R2, and FRC180-R2 beams were 22.2, 17.9, and $17.8 \mathrm{~mm}$, respectively. The deflection of the FRC120-R2 beam was greater than that of the other beams, and the deflections at the ultimate states of the FRC150-R2 and FRC180-R2 beams were similar. With regard to the beams with a rebar ratio of $0.89 \%(\mathrm{R} 3)$, the deflections at the ultimate states of the FRC120-R3, FRC150-R3, and FRC180$\mathrm{R} 3$ beams were $20.9,34.6$, and $21.2 \mathrm{~mm}$, respectively. At the ultimate state, the FRC150-R3 beam showed the greatest deflection and the deflections of the FRC120-R3 and FRC180-R3 beams were similar. With regard to the beams with a rebar ratio of $1.19 \%(\mathrm{R} 4)$, the ultimate deflection of the
FRC150-R4 beam was the greatest. Therefore, the deflection at the ultimate state of a UHPFRC beam is not directly affected by the compressive strength of UHPFRC, while the bending strength of a UHPFRC beam is approximately proportionally affected by the compressive strength of concrete.

The load-deflection relationship of a beam subjected to bending depends on the curvature along the axis of the beam. In a low-loading state, because the widths of the cracks in the constant moment region are small and uniform, the curvature in this region is relatively uniform; this results in deflection, which depends on the constant curvature. However, if a major crack forms, the curvature in the constant moment region will no longer be uniform; thus, the midspan deflection of the beam will not depend on the constant curvature. As shown in Figure 8, a major crack appeared in all the test beams. Therefore, the experimental results of the midspan deflection at the ultimate state did not show an obvious trend with the compressive strength of UHPFRC.

\section{Estimating the Tensile Behavior of UHPFRC Beams}

4.1. Method for Predicting the Bending Moment-Curvature Relationship. In this study, a sectional analysis was performed by using a multilayer section to predict the bending strength of UHPFRC beams. The cross section of the test beam is divided into several layers along the height, and it is assumed that the compression and tensile strain are both linear throughout the cross section. The compressive strain at the top layer and the tensile strain at the bottom layer of the cross section are calculated by using two variables: the cross-sectional curvature $(\varphi)$ and the distance from the top layer to the neutral axis $(c)$. 


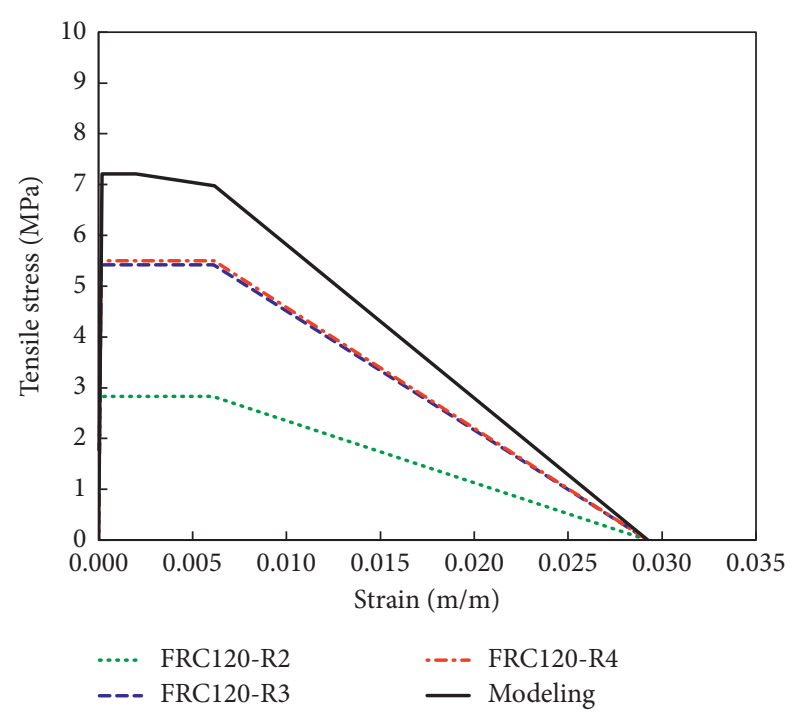

(a) FRC120 series

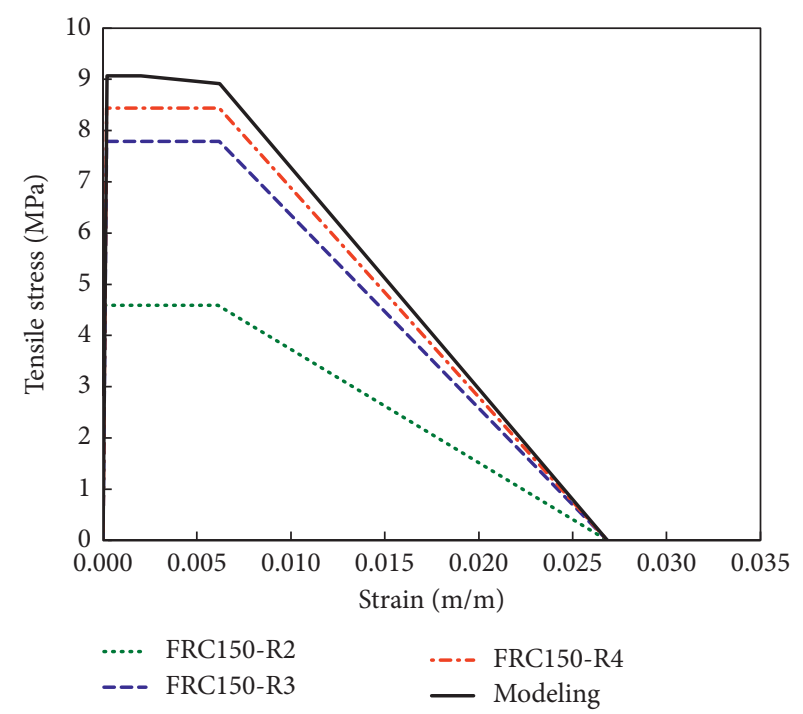

(b) FRC150 series

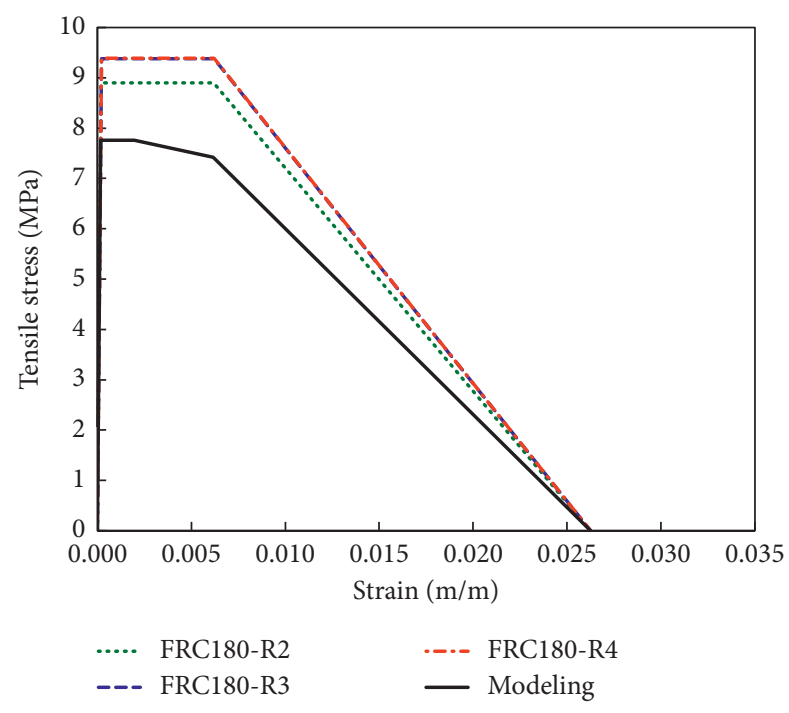

(c) FRC180 series

FIgURE 5: Modeling and estimation of the tensile behavior of UHPFRC.

TABLE 2: Material modeling of the UHPFRC.

\begin{tabular}{lccccccccc}
\hline \multirow{2}{*}{ Mixture } & \multicolumn{3}{c}{ Compressive behavior } & \multicolumn{5}{c}{ Tensile behavior } \\
& $f_{\mathrm{ck}}(\mathrm{MPa})$ & $\varepsilon_{\mathrm{c} 0}$ & $E_{\mathrm{cm}}(\mathrm{MPa})$ & $f_{\mathrm{cttk}}(\mathrm{MPa})$ & $f_{\mathrm{ctf}, 1 \%, \mathrm{k}}(\mathrm{MPa})$ & $\varepsilon_{\mathrm{el}}$ & $\varepsilon_{\text {peak }}$ & $\varepsilon_{1 \%}$ & $\varepsilon_{\text {lim }}$ \\
\hline FRC120 & 133.7 & 0.0033 & 40,150 & 7.21 & 6.98 & 0.00018 & 0.00198 & 0.00618 & 0.02925 \\
FRC150 & 148.8 & 0.0034 & 43,220 & 9.07 & 9.07 & 0.00021 & 0.00201 & 0.00621 & 0.02685 \\
FRC180 & 181.2 & 0.0040 & 45,140 & 7.76 & 7.76 & 0.00017 & 0.00197 & 0.00617 & 0.02625 \\
\hline
\end{tabular}

The terms in the table are shown in Figure 3.

The compressive strain at the top face and the tensile strain at the bottom face are calculated as follows:

$$
\begin{aligned}
\varepsilon_{\text {top }} & =c \varphi, \\
\varepsilon_{\text {bottom }} & =(h-c) \varphi,
\end{aligned}
$$

where $h$ is the beam height.
After the strains in the top and bottom layers are determined, the strain in the other layers can be obtained, as shown in Figure 10, because the strain distribution is assumed to be linear throughout the cross section. Then, the stress of each layer can be obtained from the material model. In addition, the force of each layer is determined based on the stress of the UHPFRC in each layer and the stress of the steel rebar. The sum of the forces 


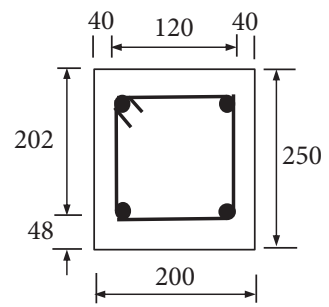

Longitudinal rebar: D13

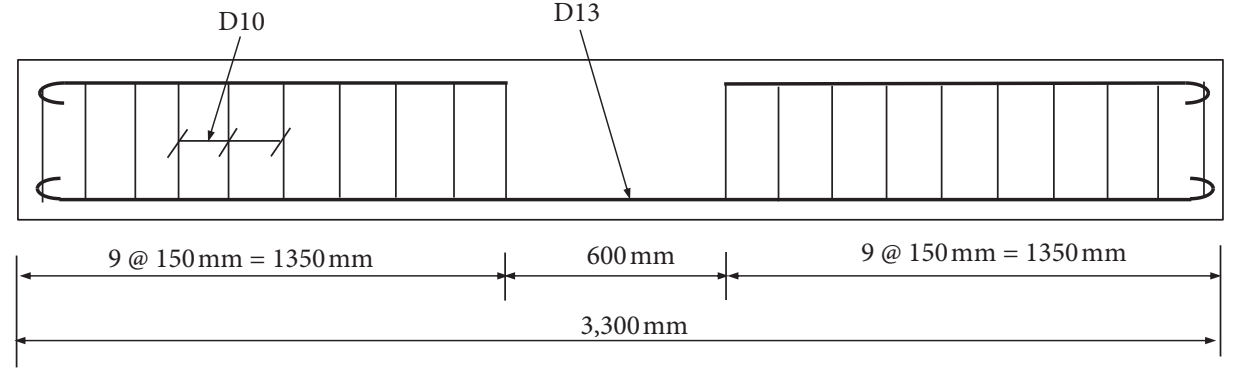

Figure 6: Dimensions of the beam.

TABLE 3: Details of the beams.

\begin{tabular}{|c|c|c|c|c|c|c|c|c|c|c|}
\hline \multirow[b]{2}{*}{ Beams } & \multirow[b]{2}{*}{$\begin{array}{c}\text { Target } \\
\text { compressive } \\
\text { strength } \\
(\mathrm{MPa})\end{array}$} & \multirow[b]{2}{*}{$\begin{array}{c}\text { Mean } \\
\text { compressive } \\
\text { strength } \\
(\mathrm{MPa})\end{array}$} & \multirow[b]{2}{*}{$\begin{array}{l}\text { Fiber } \\
\text { volume } \\
\text { content, } V_{\mathrm{f}} \\
(\%)\end{array}$} & \multicolumn{3}{|c|}{ Beam dimensions } & \multicolumn{4}{|c|}{ Rebar } \\
\hline & & & & $\begin{array}{l}\text { Width of } \\
\text { section, } b \\
(\mathrm{~mm})\end{array}$ & $\begin{array}{l}\text { Height of } \\
\text { section, } h \\
(\mathrm{~mm})\end{array}$ & $\begin{array}{c}\text { Effective } \\
\text { depth of } \\
\text { beam, } a \\
(\mathrm{~mm})\end{array}$ & Number & $\begin{array}{c}\text { Area, } \\
A_{\mathrm{s}} \\
\left(\mathrm{mm}^{2}\right)\end{array}$ & $\begin{array}{l}\text { Rebar } \\
\text { ratio, } \rho \\
(\%)\end{array}$ & $\begin{array}{l}\text { Yielding } \\
\text { strength, } f_{\mathrm{y}} \\
\quad(\mathrm{MPa})\end{array}$ \\
\hline 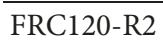 & & & & 200 & 250 & 213.5 & 2-D13 & 258 & 0.59 & 420 \\
\hline FRC120-R3 & 120 & 133.7 & 1.0 & 200 & 250 & 213.5 & 3-D13 & 387 & 0.89 & 420 \\
\hline FRC120-R4 & & & & 200 & 250 & 213.5 & 4-D13 & 516 & 1.19 & 420 \\
\hline FRC150-R2 & & & & 200 & 250 & 213.5 & 2-D13 & 258 & 0.59 & 420 \\
\hline FRC150-R3 & 150 & 148.8 & 1.5 & 200 & 250 & 213.5 & 3-D13 & 387 & 0.89 & 420 \\
\hline FRC150-R4 & & & & 200 & 250 & 213.5 & 4-D13 & 516 & 1.19 & 420 \\
\hline FRC180-R2 & & & & 200 & 250 & 213.5 & 2-D13 & 258 & 0.59 & 420 \\
\hline FRC180-R3 & 180 & 181.2 & 1.5 & 200 & 250 & 213.5 & $3-\mathrm{D} 13$ & 387 & 0.89 & 420 \\
\hline FRC180-R4 & & & & 200 & 250 & 213.5 & 4-D13 & 516 & 1.19 & 420 \\
\hline
\end{tabular}

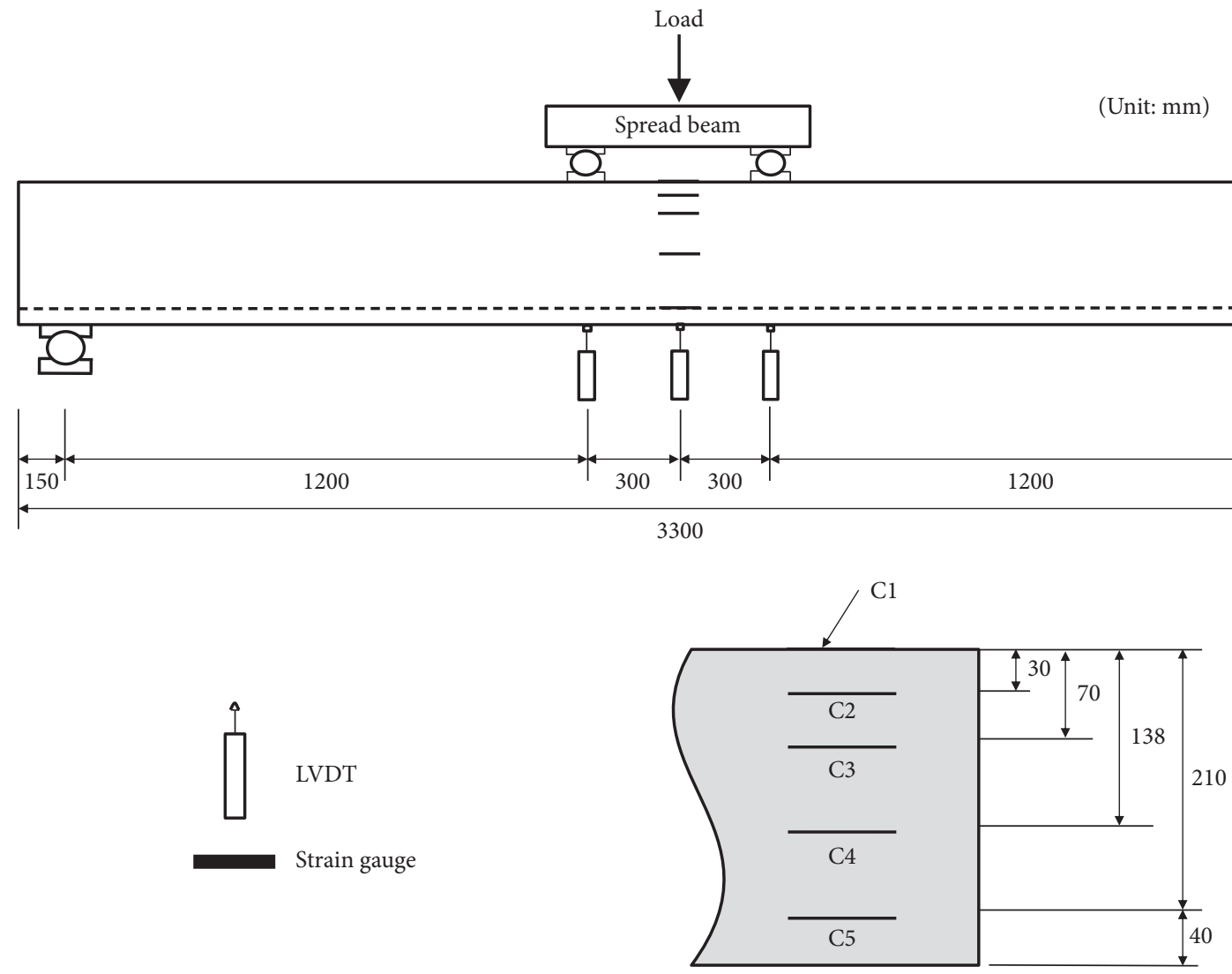

FIGURE 7: Instrumentation used for the flexural tests of the beams. 


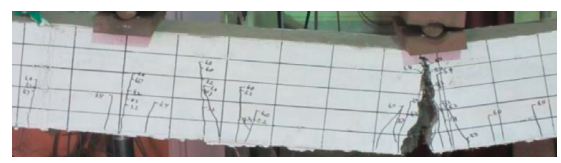

FRC120-R2 beam

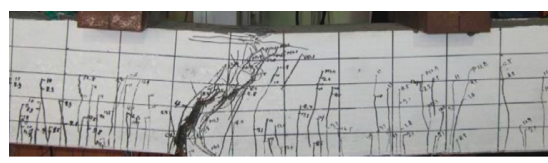

FRC180-R2 beam

(a) Rebar ratio of $0.59 \%$ (R2)

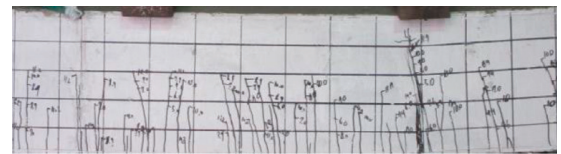

FRC120-R3 beam

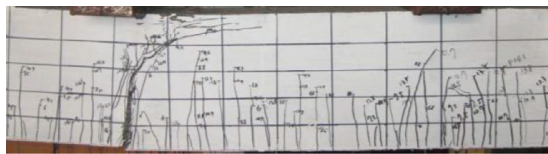

FRC180-R3 beam

(b) Rebar ratio of $0.89 \%$ (R3)

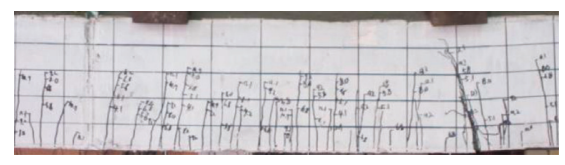

FRC120-R4 beam

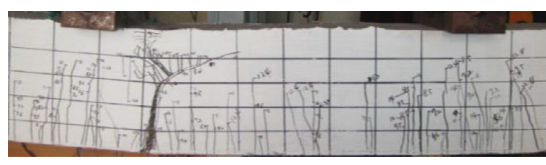

FRC180-R4 beam

(c) Rebar ratio of $1.19 \%(\mathrm{R} 4)$

FIGURE 8: Cracking and failure of the UHPFRC beams.

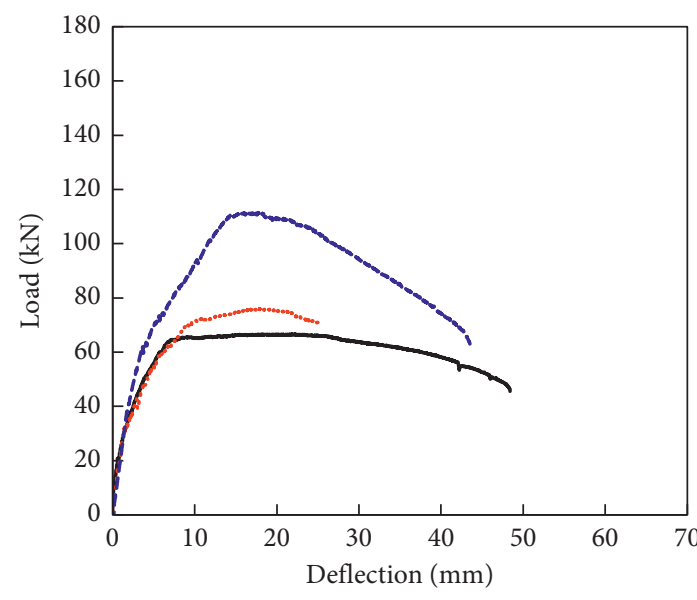

- FRC120-R2

…. FRC150-R2

--- FRC180-R2

(a) Rebar ratio of $0.59 \%$ (R2)

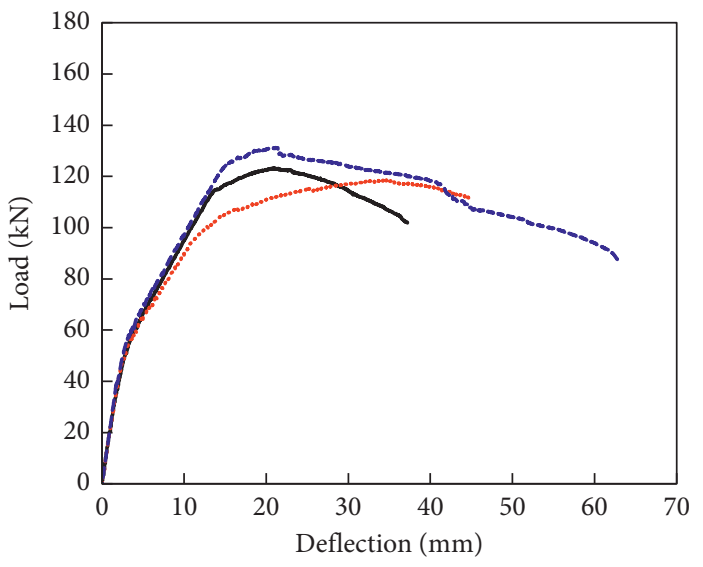

- FRC120-R3

.... FRC150-R3

--- FRC180-R3

(b) Rebar ratio of $0.89 \%(\mathrm{R} 3)$

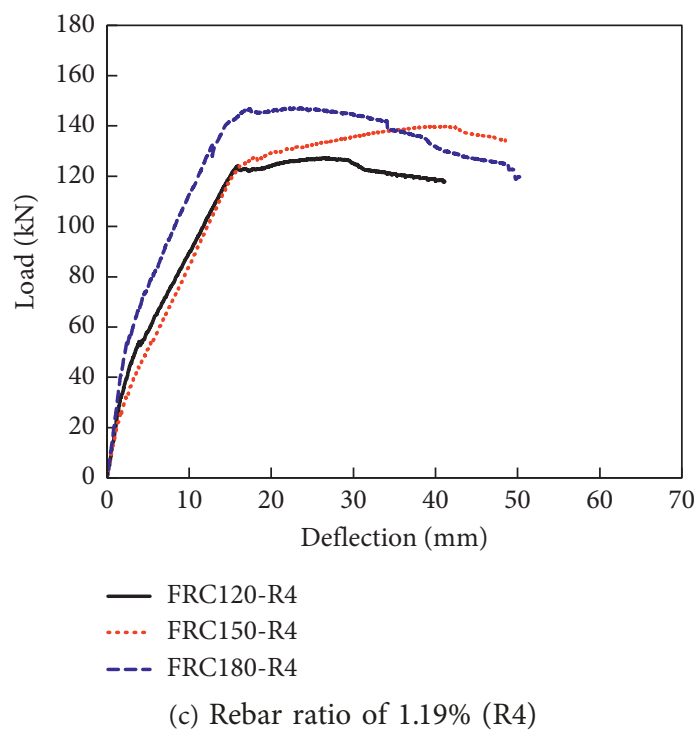

Figure 9: Load-deflection relationship curves. 
TABLe 4: Experimental results of the beams.

\begin{tabular}{|c|c|c|c|c|c|c|c|c|c|}
\hline \multirow[b]{2}{*}{ Beams } & \multicolumn{3}{|c|}{ Initial cracking stage } & \multicolumn{3}{|c|}{ Yielding stage } & \multicolumn{3}{|c|}{ Ultimate stage } \\
\hline & $\begin{array}{l}\text { Initial } \\
\text { cracking } \\
\text { load, } P_{\mathrm{cr}} \\
(\mathrm{kN})\end{array}$ & $\begin{array}{c}\text { Initial } \\
\text { cracking } \\
\text { moment, } M_{\mathrm{cr}} \\
(\mathrm{kN} \cdot \mathrm{m})\end{array}$ & $\begin{array}{c}\text { Initial } \\
\text { cracking } \\
\text { deflection, } \Delta_{\mathrm{cr}} \\
(\mathrm{mm})\end{array}$ & $\begin{array}{l}\text { Yielding } \\
\text { load, } P_{\mathrm{y}} \\
(\mathrm{kN})\end{array}$ & $\begin{array}{c}\text { Yielding } \\
\text { moment, } \\
M_{\mathrm{y}} \\
(\mathrm{kN} \cdot \mathrm{m})\end{array}$ & $\begin{array}{c}\text { Yielding } \\
\text { deflection, } \\
\Delta_{\mathrm{y}} \\
(\mathrm{mm})\end{array}$ & $\begin{array}{l}\text { Ultimate } \\
\text { load, } \\
P_{\mathrm{u}}(\mathrm{kN})\end{array}$ & $\begin{array}{c}\text { Ultimate } \\
\text { moment, } \\
M_{\mathrm{u}} \\
(\mathrm{kN} \cdot \mathrm{m}) \\
\end{array}$ & $\begin{array}{c}\text { Ultimate } \\
\text { deflection, } \\
\Delta_{\mathrm{u}}(\mathrm{mm})\end{array}$ \\
\hline FRC120-R2 & 32.0 & 19.2 & 4.1 & 63.5 & 38.1 & 6.7 & 66.7 & 40.0 & 22.2 \\
\hline FRC120-R3 & 60.1 & 36.1 & 4.0 & 117.2 & 70.3 & 15.3 & 123.3 & 74.0 & 20.9 \\
\hline FRC120-R4 & 54.6 & 32.8 & 4.2 & 123.8 & 74.3 & 15.8 & 127.3 & 76.4 & 26.4 \\
\hline FRC150-R2 & 41.0 & 24.6 & 2.5 & 71.5 & 42.9 & 11.0 & 76.0 & 45.6 & 17.9 \\
\hline FRC150-R3 & 48.4 & 29.0 & 2.6 & 107.7 & 64.6 & 31.7 & 118.6 & 71.2 & 34.6 \\
\hline FRC150-R4 & 44.1 & 26.5 & 3.8 & 123.9 & 74.3 & 16.1 & 139.9 & 83.9 & 39.5 \\
\hline FRC180-R2 & 41.1 & 24.7 & 1.9 & 105.3 & 63.2 & 12.8 & 111.5 & 66.9 & 17.8 \\
\hline FRC180-R3 & 40.8 & 24.5 & 1.8 & 122.0 & 73.2 & 14.4 & 131.3 & 78.8 & 21.2 \\
\hline FRC180-R4 & 41.0 & 24.6 & 1.7 & 126.9 & 76.1 & 12.0 & 147.2 & 88.3 & 25.5 \\
\hline
\end{tabular}

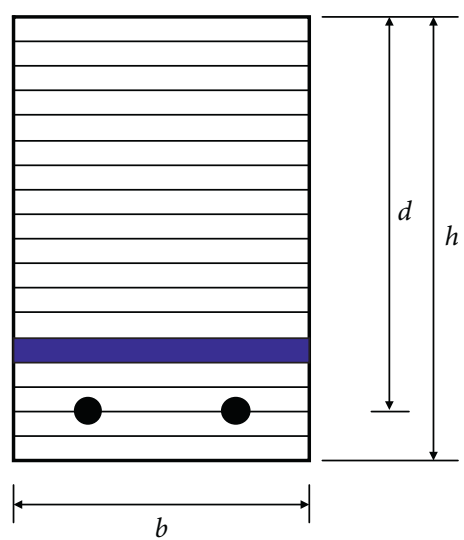

(a) Cross section

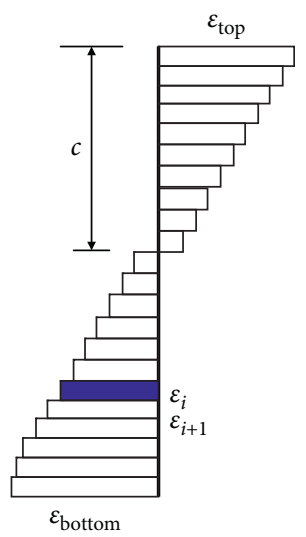

(b) Strain distribution

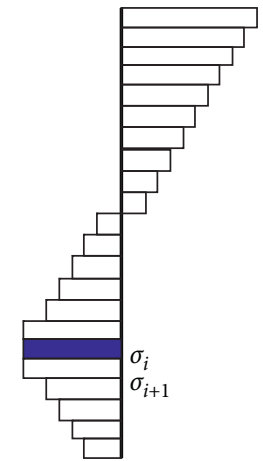

(c) Stress distribution

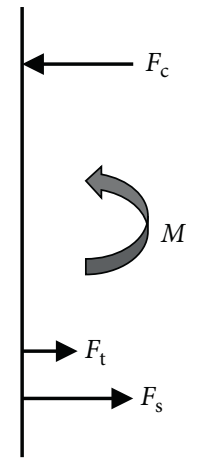

(d) Equilibrium of forces

FIgURE 10: Strain compatibility and equilibrium forces in sectional analysis.

for each section should satisfy the equilibrium condition. When the forces throughout the cross section are in equilibrium, the bending moment can finally be determined.

\subsection{Prediction of the Bending Capacity and Estimation of the} Tensile Strength of UHPFRC Beams. To predict the bending behavior of UHPFRC beams, two analytical approaches were used in this study. In the first approach, which is shown schematically in Figure 11, the tensile properties obtained from the CMOD test results were used as the input for the sectional analysis to obtain the moment-curvature relationship, after which the analysis result of the momentcurvature curve was compared with the experimental result. Comparisons of the analysis results and experimental results for the moment-curvature relationships are shown in Figures 12-14, in which the relationships between the moment and curvature obtained from the beam tests are plotted using the strain measurements from the beam surface. The measured strain profile along the beam height can be used to determine the curvature. However, individual strain measurements became unreliable after the crack observed at the surface of the concrete beam widened; consequently, not all curvatures are shown in the momentcurvature relationships.
The analysis result of the bending moment of the FRC120-R2 beam overestimated the experimental result, as shown in Figure 12; the ratio of the analysis result to the experimental result for the bending strength is 1.54 , as shown in Table 5. Meanwhile, the analysis results of the bending strengths of the FRC120-R3 and FRC120-R4 beams were slightly greater than the experimental results; thus, the ratios of the analysis results to the test results for these two beams are 0.99 and 1.10 , respectively.

For the FRC150 beam series, the analysis result of the bending moment of the FRC150-R2 beam overestimated the test result greatly; thus, the ratio of the analysis result to the experimental result for the bending strength is 1.46. Meanwhile, the analysis results of the bending moments of the FRC150-R2 and FRC150-R3 beams were in good agreement with the experimental results; thus, the ratios of the analysis results to the experimental results are 1.06 and 1.01, respectively.

In contrast to the FRC120 and FRC150 beam series, the analysis results of the FRC180 beam series were underestimated. The analysis results of the bending strengths of the FRC180-R2, FRC180-R3, and FRC180-R4 beams were less than the corresponding experimental results, with analytical-experimental result ratios of $0.92,0.90$, and 0.92 , respectively. 


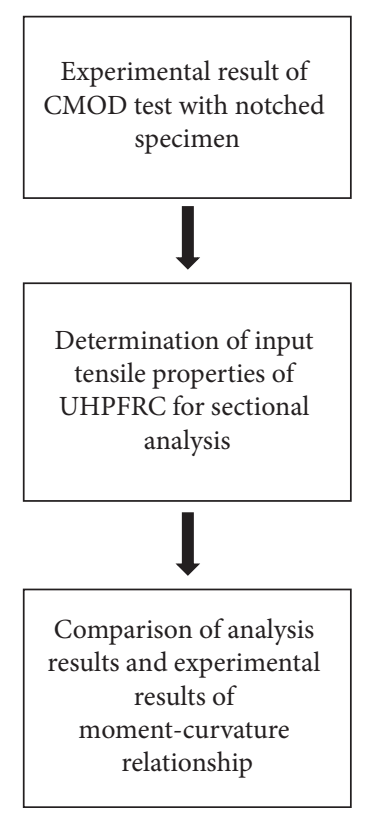

(a) Approach I

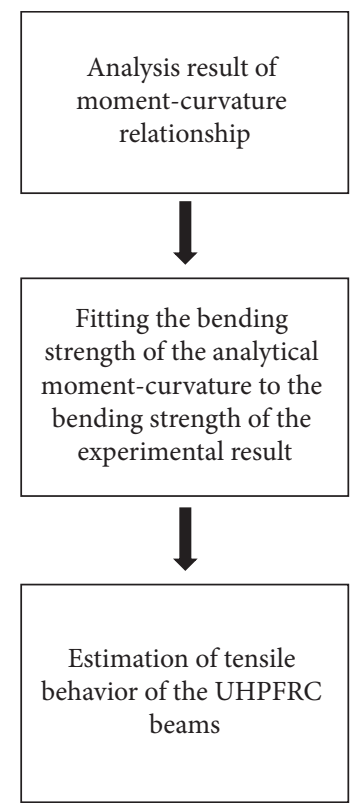

(b) Approach II

FIGURE 11: Approaches for estimating the tensile behavior of a UHPFRC beam.

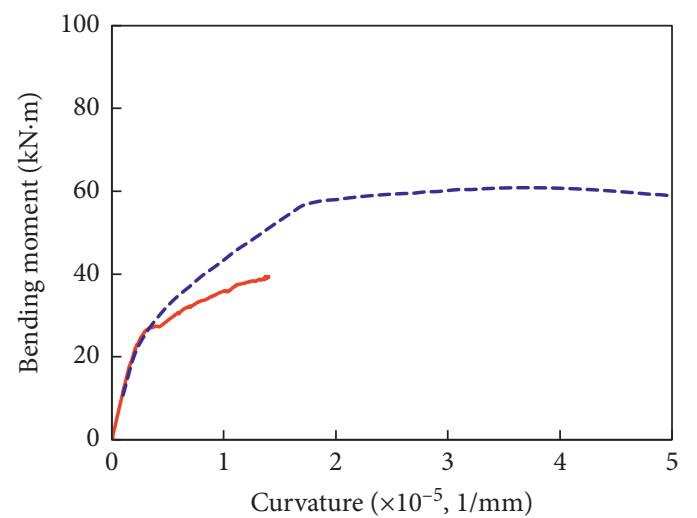

Experimental result --- Analysis result

(a) FRC120-R2 beam

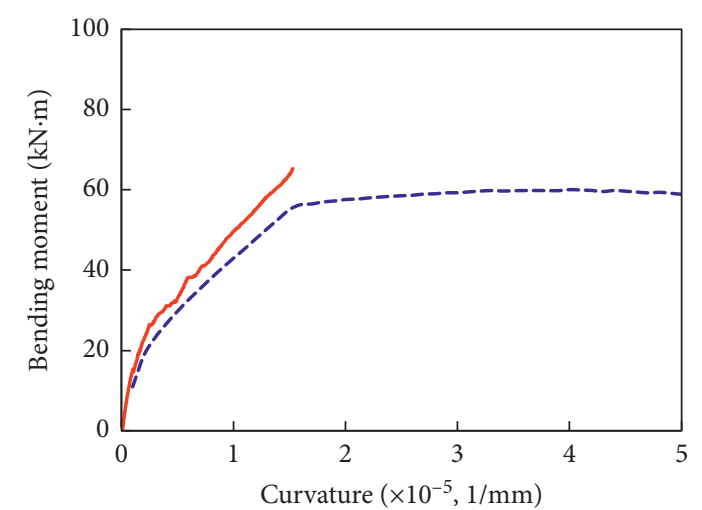

Experimental result

--- Analysis result

(b) FRC120-R3 beam

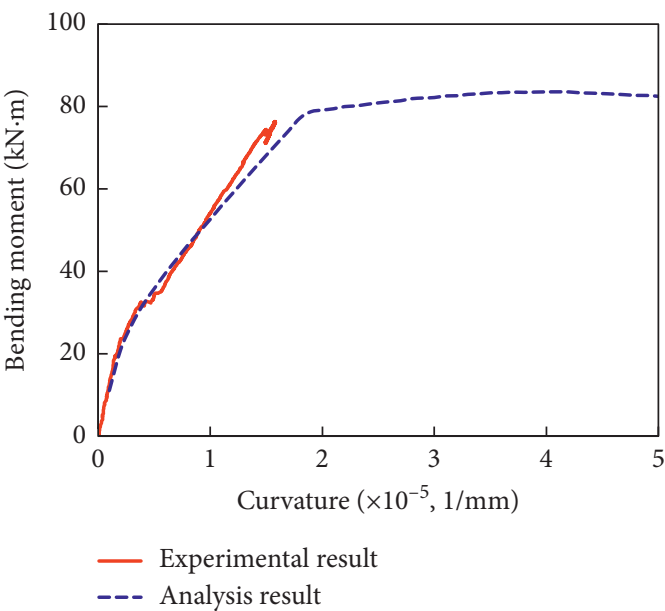

(c) FRC120-R4 beam

Figure 12: Prediction of moment-curvature curves (FRC120 series beams). 


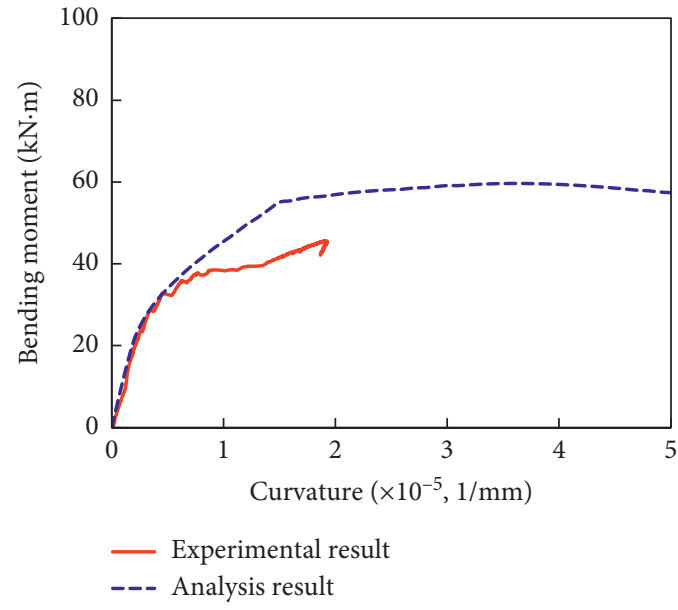

(a) FRC150-R2 beam

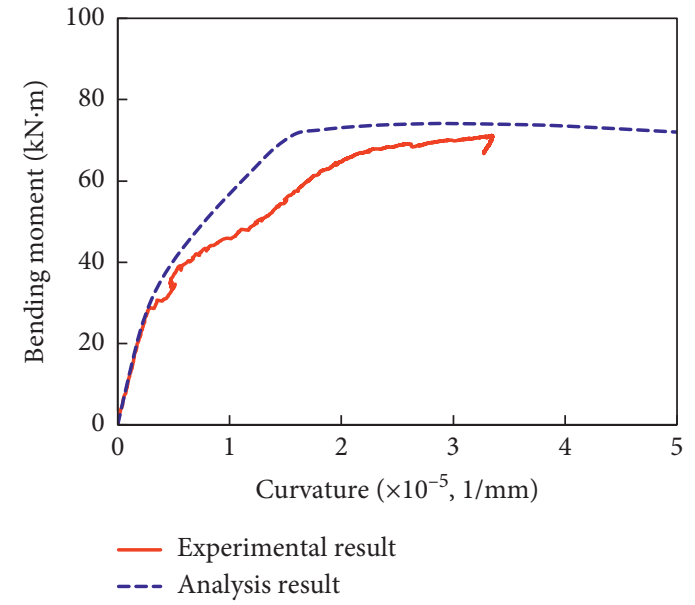

(b) FRC150-R3 beam

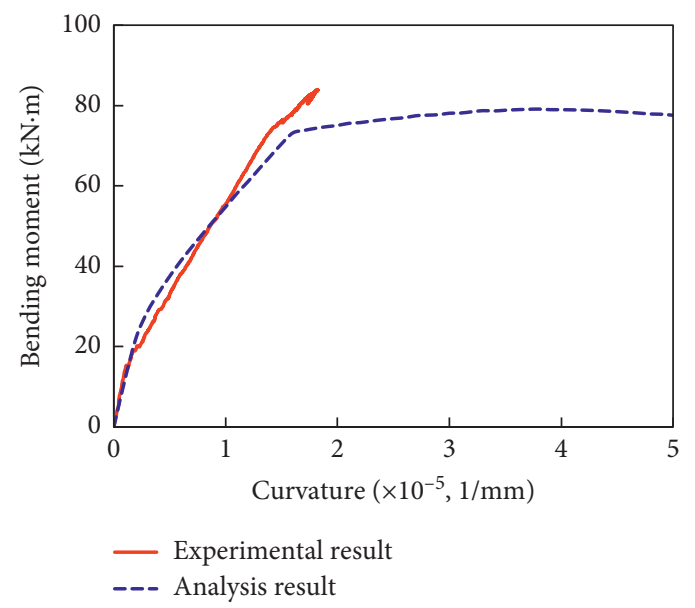

(c) FRC150-R4 beam

FIgURE 13: Prediction of moment-curvature curves (FRC150 series beams).

The most important parameter for predicting the bending moment-curvature curve of UHPFRC is the tensile strength. It is well known that an accurate prediction of the bending strength of a UHPFRC beam is dependent on the tensile strength of the UHPFRC. The deviation of the analysis result from the experimental result of the bending strength may primarily be due to the difference between the tensile strength obtained from the material test with the notched specimen and the actual tensile strength of the test beam.

Therefore, a second approach was employed to estimate the actual tensile strength of each test beam. In the second approach, a sectional analysis was performed for the momentcurvature curve to ensure that the bending strength of the analytical moment-curvature curve was in good agreement with that of the experimental result. The fitting of the bending strengths from the analytical moment-curvature curves and from the experimental work is illustrated in Figures 15-17.

The tensile strength of UHPFRC is a major parameter influencing the bending capacity of a UHPFRC beam. If the bending strength of the analysis result is almost identical to the experimental result, the tensile properties used as input for the sectional analysis can be assumed to be the actual tensile properties for the test beam.
The tensile strengths obtained from the material testing with the notched specimens and estimated by fitting the bending strengths of the analytical moment-curvature curves to the experimental result (shown in Figures 1517) are listed in Table 5. The findings reveal that the tensile strength obtained from the material testing is different from the tensile strength estimated by fitting the momentcurvature curves between the analysis and experimental results. For example, for the FRC120 and FRC150 beam series, the tensile strength obtained from the tensile test of the notched UHPFRC specimens was greater than that estimated by fitting the bending strength determined from the analytical moment-curvature curve to that determined experimentally.

From the test of the notched prismatic specimen, the tensile strength of the FRC120 beam series was 7.21 MPa, while the estimated tensile strengths of the FRC120-R2, FRC120-R3, and FRC120-R4 beams were 2.83, 5.42, and $5.50 \mathrm{MPa}$, respectively. The tensile strength of the FRC150 beam series obtained from the test on the prismatic specimen was 9.07 MPa, while the estimated tensile strengths of the FRC150R2, FRC150-R3, and FRC150-R4 beams were 4.59, 7.79, and 8.44 MPa, respectively. Meanwhile, the tensile strength of the 


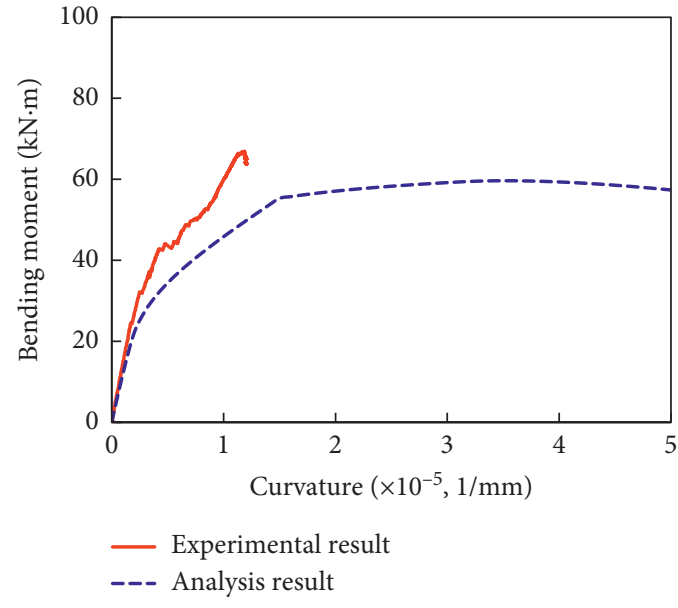

(a) FRC180-R2 beam

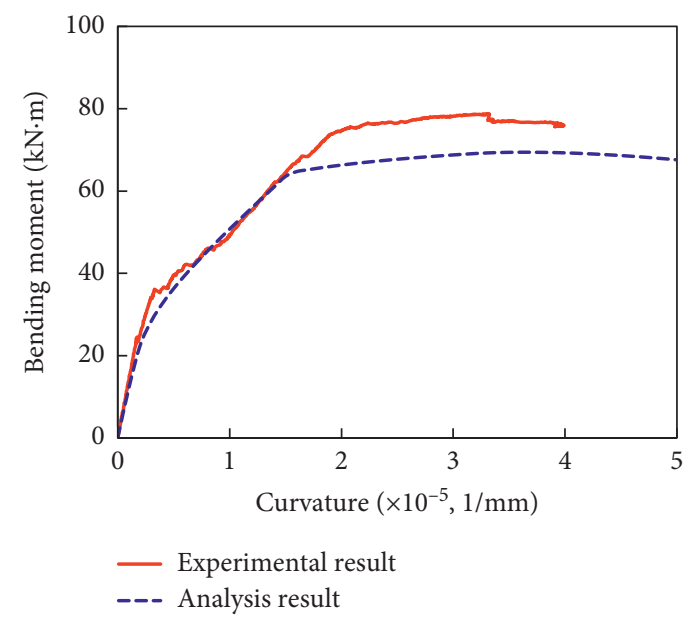

(b) FRC180-R3 beam

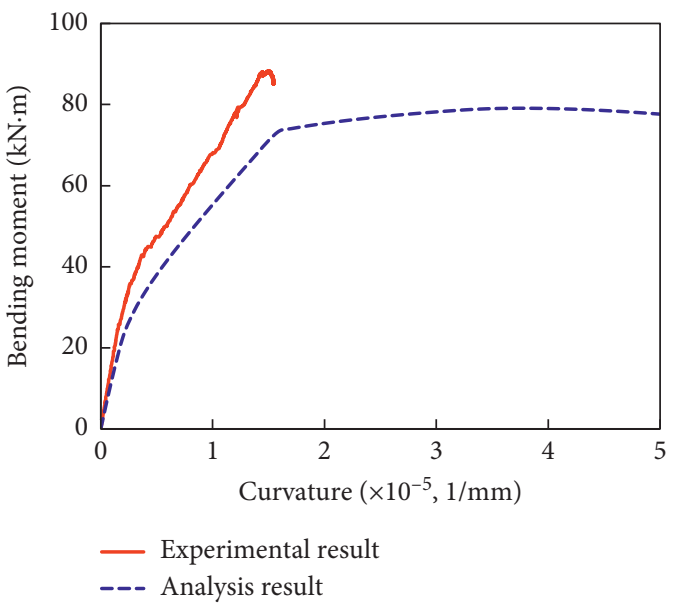

(c) FRC180-R4 beam

FIGURE 14: Prediction of moment-curvature curves (FRC180 series beams).

TABle 5: Analysis results.

\begin{tabular}{|c|c|c|c|c|c|c|}
\hline \multirow[b]{2}{*}{ Beams } & \multicolumn{2}{|c|}{ Tensile strength $(\mathrm{MPa})$} & \multicolumn{2}{|r|}{ Bending strength $(\mathrm{kN} \cdot \mathrm{m})$} & \multirow{2}{*}{$\begin{array}{l}\text { Ratio } \\
(2) /(1)\end{array}$} & \multirow{2}{*}{$\begin{array}{c}\text { Difference } \\
\text { between tensile } \\
\text { strengths* (\%) }\end{array}$} \\
\hline & $\begin{array}{l}\text { CMOD test } \\
\text { result }\left(f_{\mathrm{t}, \text { test }}\right)\end{array}$ & $\begin{array}{l}\text { Estimation from curve } \\
\text { fitting }\left(f_{t, \text { estimation }}\right)\end{array}$ & $\begin{array}{l}\text { Beam test } \\
\text { result }(1)\end{array}$ & $\begin{array}{l}\text { Prediction using the tensile } \\
\text { strength from the CMOD test (2) }\end{array}$ & & \\
\hline FRC120-R2 & 7.21 & 2.83 & 40.0 & 61.7 & 1.54 & 154.8 \\
\hline FRC120-R3 & 7.21 & 5.42 & 74.0 & 73.0 & 0.99 & 33.0 \\
\hline FRC120-R4 & 7.21 & 5.50 & 76.4 & 84.4 & 1.10 & 31.1 \\
\hline FRC150-R2 & 9.07 & 4.59 & 45.6 & 66.6 & 1.46 & 97.6 \\
\hline FRC150-R3 & 9.07 & 7.79 & 71.2 & 75.8 & 1.06 & 16.4 \\
\hline FRC150-R4 & 9.07 & 8.44 & 83.9 & 85.0 & 1.01 & 7.5 \\
\hline FRC180-R2 & 7.76 & 8.90 & 66.9 & 61.5 & 0.92 & 12.8 \\
\hline FRC180-R3 & 7.76 & 9.38 & 78.8 & 71.2 & 0.90 & 17.3 \\
\hline FRC180-R4 & 7.76 & 9.39 & 88.3 & 80.9 & 0.92 & 17.4 \\
\hline
\end{tabular}

* Difference between the tensile strength obtained from the material test and that estimated by fitting the moment-curvature curves.

FRC180 beam series obtained from the tensile test was $10 \%$ less than that estimated by fitting the moment-curvature curve.

\section{Conclusions}

An experimental study on the flexural behavior of UHPFRC is presented in this study, and the tensile strength of
UHPFRC beams is estimated by fitting the analysis result of the moment-curvature curve to the experimental result of the bending strength. Based on the experimental and analysis results, the following conclusions can be made:

(1) The width of one of the well-distributed cracks in the constant moment zone was significantly widened, and the crack became localized. The localization of 


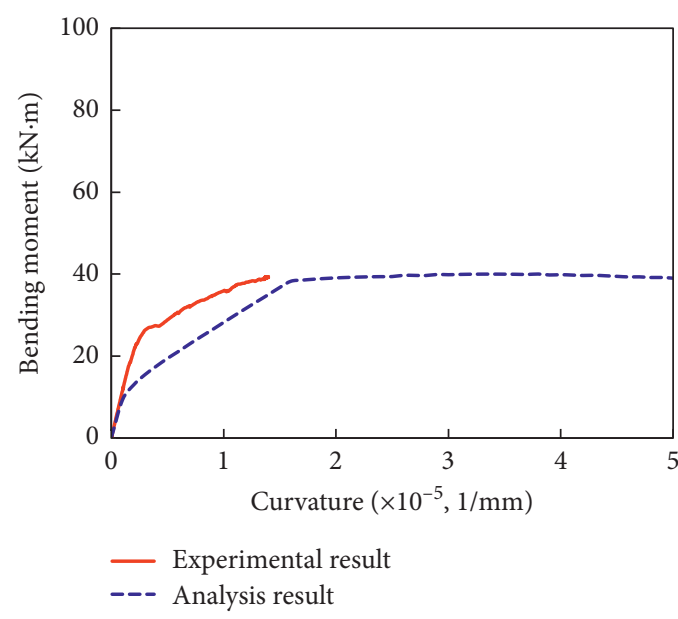

(a) FRC120-R2 beam

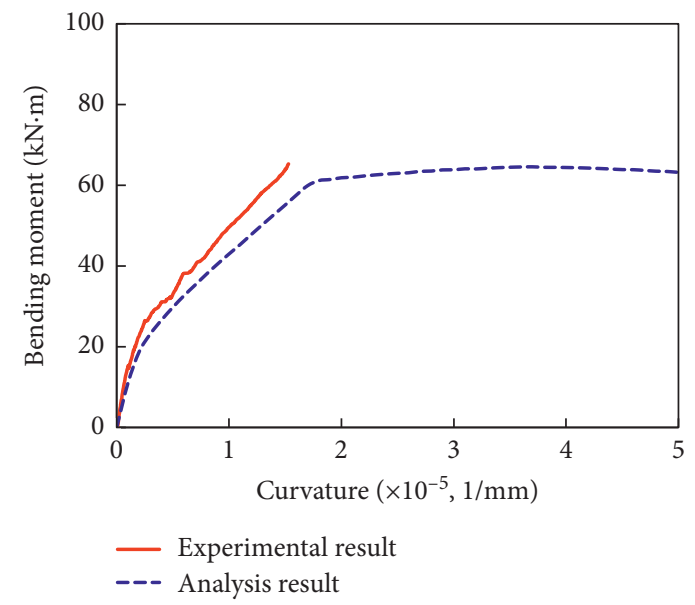

(b) FRC120-R3 beam

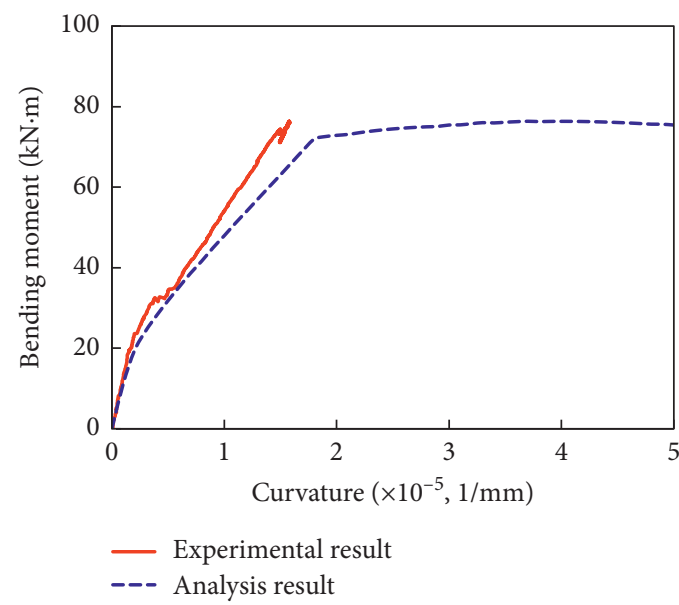

(c) FRC120-R4 beam

FiguRE 15: Fitting of moment-curvature curves between the experimental and analysis results (FRC120 series beams).

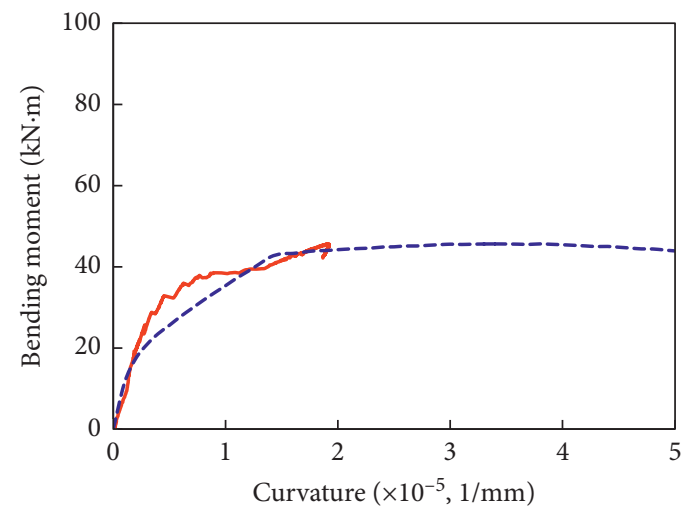

- Experimental result

--- Analysis result

(a) FRC150-R2 beam

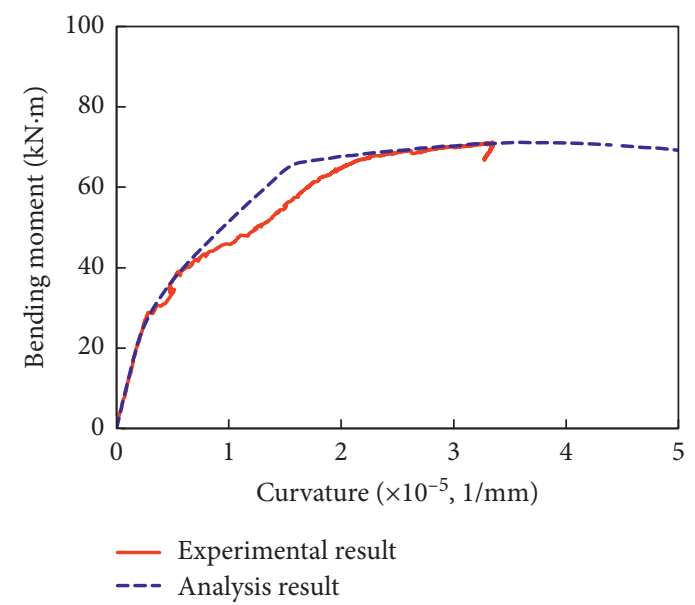

(b) FRC150-R3 beam

FIGURE 16: Continued. 


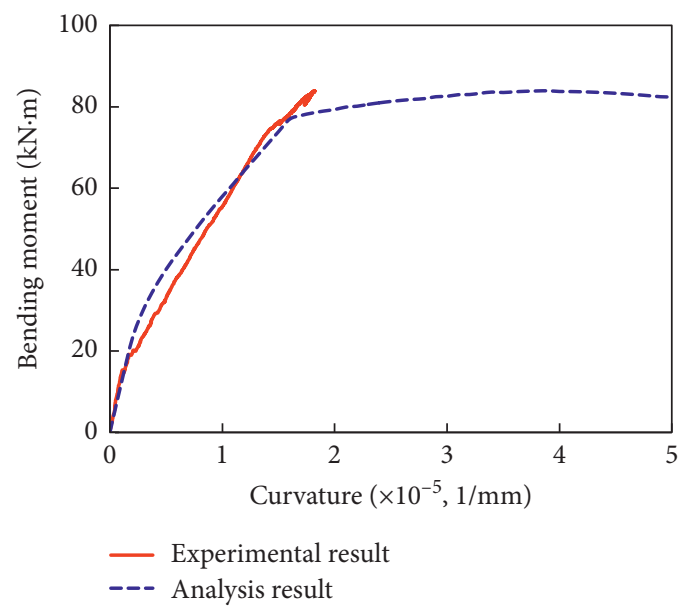

(c) FRC150-R4 beam

FIGURE 16: Fitting of moment-curvature curves between the experimental and analysis results (FRC150 series beams).

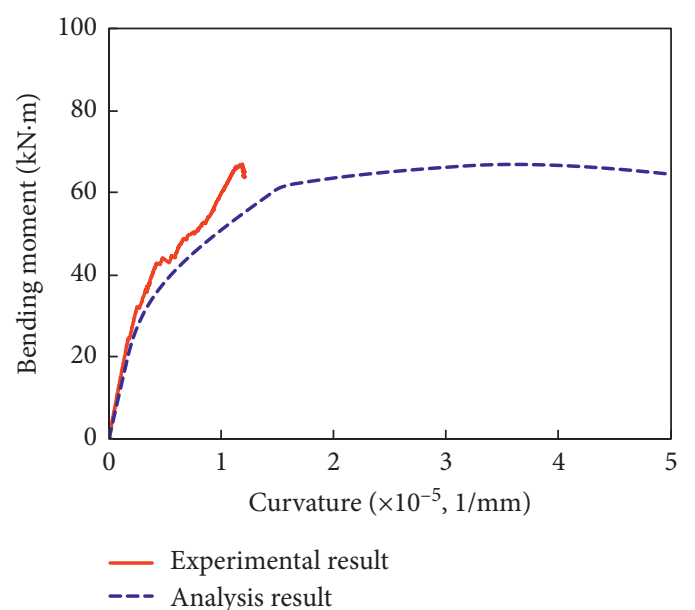

(a) FRC180-R2 beam

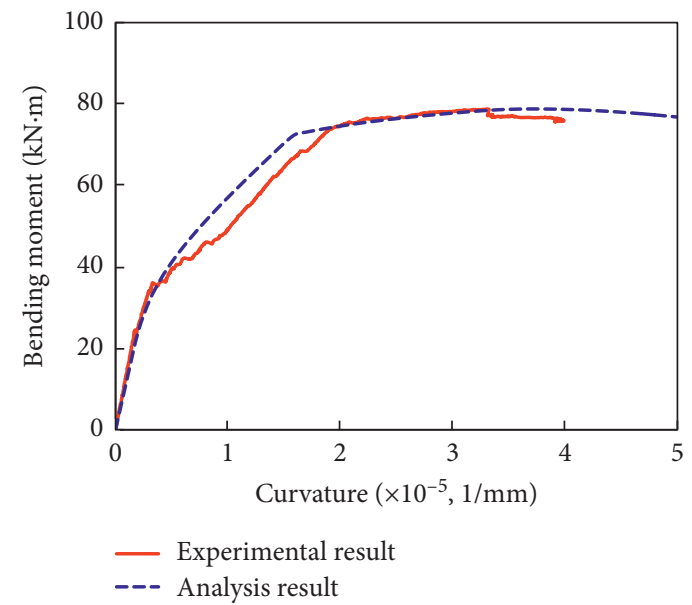

(b) FRC180-R3 beam

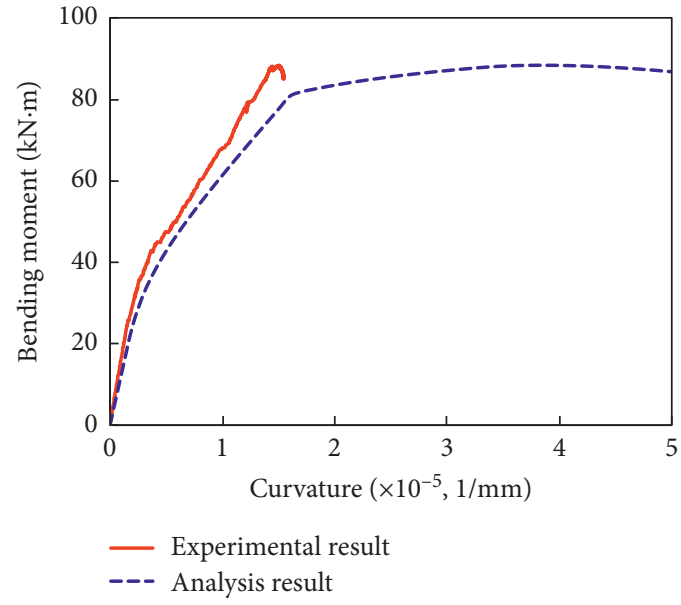

(c) FRC180-R4 beam

FIGURE 17: Fitting of moment-curvature curves between the experimental and analysis results (FRC180 series beams).

cracks within the constant moment region caused the bridging effect to weaken, and steel fibers were eventually pulled out of the matrix in the region of localized cracking.
(2) The bending strengths of the FRC150 and FRC180 beam series were greater than those of the FRC120 beam series, indicating that the flexural strength of the UHPFRC beams increased with the steel fiber content. 
(3) The bending strength obtained from the sectional analysis using the material test result was compared with the beam test result. This comparison showed that the bending strengths of several beams differed from the corresponding test results, thereby indicating that the tensile strength obtained from the material test would be significantly different from that estimated from the beam test results. The estimated tensile strengths of the FRC120-R2, FRC120R3, and FRC120-R4 beams were 60.7, 24.8, and $23.7 \%$ less than the tensile strength obtained from the material test, respectively. Similarly, the estimated tensile strengths of the FRC150-R2, FRC150R3, and FRC150-R4 beams were 49.4, 14.1, and 6.9\% less than the tensile strength obtained from the material test, respectively. Meanwhile, the estimated tensile strengths obtained from the FRC180 beam series were $14.7 \sim 21.0 \%$ greater than the tensile strength obtained from the material test.

(4) The tensile strengths of the UHPFRC beams were estimated reasonably by fitting the analysis results of the moment-curvature curve to the beam test results. The estimated tensile strength of the UHPFRC increased with its compressive strength.

\section{Data Availability}

The data used to support the findings of this study are available from the corresponding author upon request.

\section{Conflicts of Interest}

The authors declare that they have no conflicts of interest.

\section{Acknowledgments}

This research was supported by a grant (13SCIPA02) from the Smart Civil Infrastructure Research Program funded by the Ministry of Land, Infrastructure and Transport (MOLIT) of the Korean government and the Korea Agency for Infrastructure Technology Advancement (KAIA).

\section{References}

[1] S. H. Park, D. J. Kim, G. S. Ryu, and K. T. Koh, "Tensile behavior of ultra high performance hybrid fiber reinforced concrete," Cement and Concrete Composites, vol. 34, no. 2, pp. 172-184, 2012.

[2] S.-T. Kang, Y. Lee, Y.-D. Park, and J.-K. Kim, “Tensile fracture properties of an ultra high performance fiber reinforced concrete (UHPFRC) with steel fiber," Composite Structures, vol. 92, no. 1, pp. 61-71, 2010.

[3] S. Pyo, S. El-Tawil, and A. E. Naaman, "Direct tensile behavior of ultra high performance fiber reinforced concrete (UHPFRC) at high strain rates," Cement and Concrete Research, vol. 88, pp. 144-156, 2016.

[4] A. M. T. Hassan, S. W. Jones, and G. H. Mahmud, "Experimental test methods to determine the uniaxial tensile and compressive behaviour of ultra high performance fibre reinforced concrete (UHPFRC)," Construction and Building Materials, vol. 37, pp. 874-882, 2012.
[5] Q. Chunxiang and I. Patnaikuni, "Properties of high-strength steel fiber-reinforced concrete beams in bending," Cement and Concrete Composites, vol. 21, no. 1, pp. 73-81, 1999.

[6] A. N. Dancygier and Z. Savir, "Flexural behavior of HSFRC with low reinforcement ratios," Engineering Structures, vol. 28, no. 11, pp. 1503-1512, 2006.

[7] C. Boulay, P. Rossi, and J. L. Tailhan, "Uniaxial tensile test on a new cement composite having a hardening behaviour," in Proceeding of the sixth RILEM symposium in fibrereinforced concretes (FRC), BEFIB, Varenna, Italy, September 2004.

[8] K. Wile, S. E. Tawil, and A. E. Naaman, "Properties of strain hardening ultra-high performance fiber reinforced concrete (UHP-FRC) under direct tensile loading," Cement and Concrete Composites, vol. 48, pp. 53-66, 2014.

[9] J. Z. Su, B. C. Chen, and Q. W. Huang, "Experimental studies on the flexural behavior of UHPC beams," in Proceeding of the AFGC-ACI-fib-RILEM Int. Symposium on Ultra-High Performance Fibre-Reinforced Concrete, UHPFRC, Montpellier, France, October 2017.

[10] H. C. Mertol, E. Baran, and H. J. Bello, "Flexural behavior of lightly and heavily reinforced steel fiber concrete beams," Construction and Building Materials, vol. 98, pp. 185-193, 2015.

[11] Y. Li, C. Guertin-Normoyle, O. Algassem, and H. Aoude, "Effects of ultra-high performance fibre reinforced concrete and high-strength steel on the flexural behaviour of reinforced concrete beams," in Proceeding of the AFGC-ACI-fib-RILEM Int. Symposium on Ultra-High Performance Fibre-Reinforced Concrete, UHPFRC, Montpellier, France, October 2017.

[12] Z. Wu, C. Shi, W. He, and L. Wu, "Effects of steel fiber content and shape on mechanical properties of ultra high performance concrete," Construction and Building Materials, vol. 103, pp. 8-14, 2016.

[13] M. Singh, A. H. Sheikh, M. S. Mohamed Ali, P. Visintin, and M. C. Griffith, "Experimental and numerical study of the flexural behaviour of ultra-high performance fibre reinforced concrete beams," Construction and Building Materials, vol. 138, pp. 12-25, 2017.

[14] G. G. K. Reddy and P. Ramadoss, "Flexural behavior of ultrahigh performance steel fiber reinforced concrete: a state of the art review," International Journal of Engineering Technology Science and Research, vol. 4, pp. 2394-3386, 2017.

[15] S. Abbas, M. L. Nehdi, and M. A. Saleem, "Ultra-high performance concrete: mechanical performance, durability, sustainability and implementation challenges," International Journal of Engineering Technology Science and Research, vol. 10, no. 3, pp. 271-295, 2017.

[16] Y. Kusumawardaningsih, E. Fehling, M. Ismail, and A. A. M. Aboubakr, "Tensile strength behavior of UHPC and UHPFRC," Procedia Engineering, vol. 125, pp. 1081-1086, 2015.

[17] G. M. Ren, H. Wu, Q. Fang, and J. Z. Liu, "Effects of steel fiber content and type on static mechanical properties of UHPCC," Construction and Building Materials, vol. 163, pp. 826-839, 2018.

[18] D.-Y. Yoo, J.-H. Lee, and Y.-S. Yoon, "Effect of fiber content on mechanical and fracture properties of ultra high performance fiber reinforced cementitious composites," Composite Structures, vol. 106, pp. 742-753, 2013.

[19] D.-Y. Yoo, Y.-S. Yoon, and N. Banthia, "Flexural response of steel-fiber-reinforced concrete beams: effects of strength, fiber content, and strain-rate," Cement and Concrete Composites, vol. 64, pp. 84-92, 2015. 
[20] A. Abrishambaf, M. Pimentel, and S. Nunes, "Influence of fibre orientation on the tensile behaviour of ultra-high performance fibre reinforced cementitious composites," Cement and Concrete Research, vol. 97, pp. 28-40, 2017.

[21] S.-T. Kang and J.-K. Kim, "Investigation on the flexural behavior of UHPCC considering the effect of fiber orientation distribution," Construction and Building Materials, vol. 28, no. 1, pp. 57-65, 2012.

[22] I. H. Yang, C. B. Joh, and B. S. Kim, "Structural behavior of ultra-high performance concrete beams subjected to bending," Engineering Structure, vol. 32, no. 11, p. 3487, 2010.

[23] H. Al-Mattarneh, "Electromagnetic quality control of steel fiber concrete," Construction and Building Materials, vol. 73, pp. 350-356, 2014.

[24] S. Nunes, M. Pimentel, F. Ribeiro, P. Milheiro-Oliveira, and A. Carvalho, "Estimation of the tensile strength of UHPFRC layers based on non-destructive assessment of the fibre content and orientation," Cement and Concrete Composites, vol. 83, pp. 222-238, 2017.

[25] B. A. Graybeal, "Compressive behavior of ultra-highperformance fiber-reinforced concrete," ACI Materials Journal, vol. 104, no. 2, pp. 146-152, 2007.

[26] AFGC-SETRA, Ultra High Performance Fibre-Reinforced, Recommendations, AFGC, Paris, France, Revised edition, 2013. 


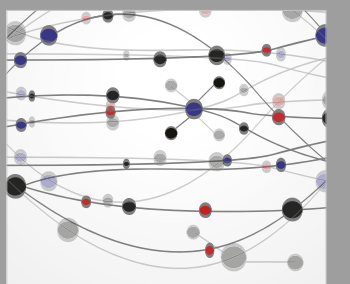

The Scientific World Journal
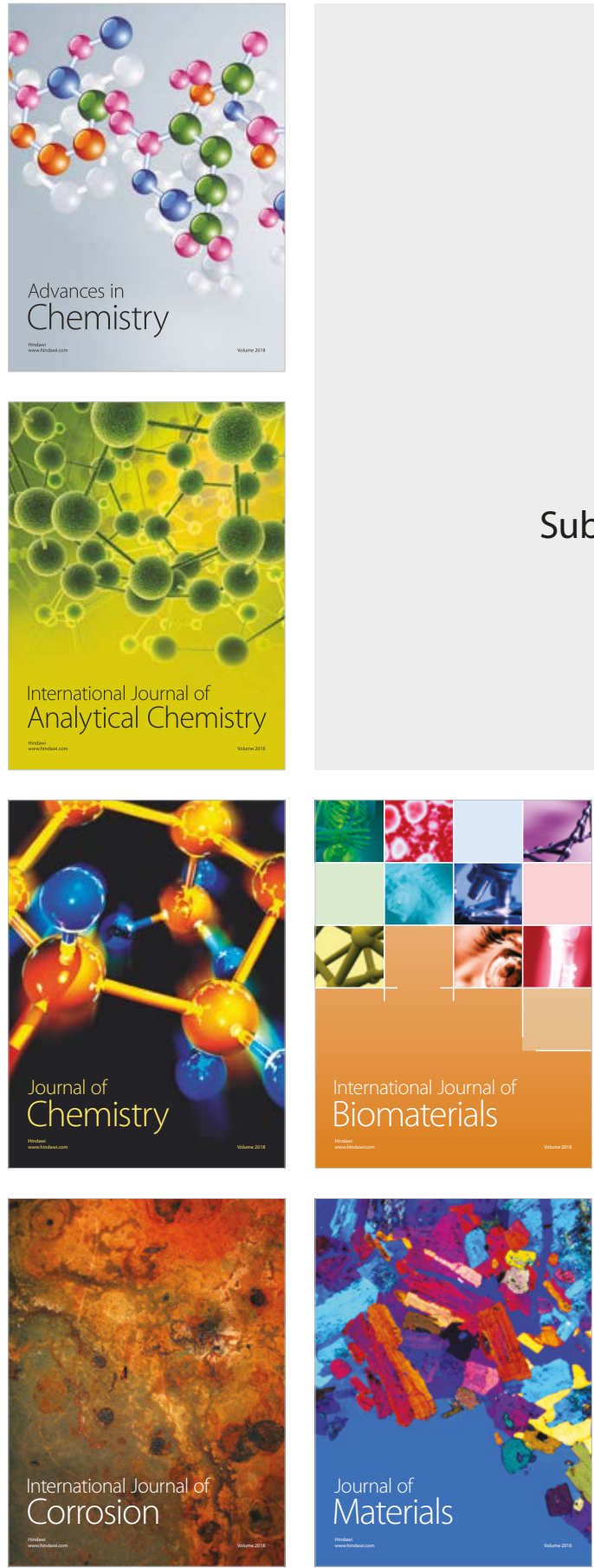

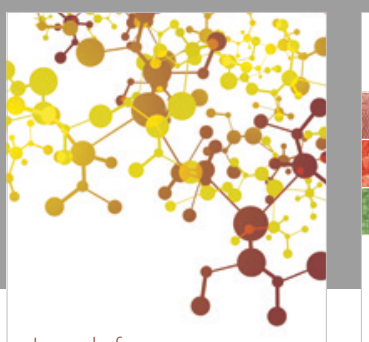

Journal of

Applied Chemistry
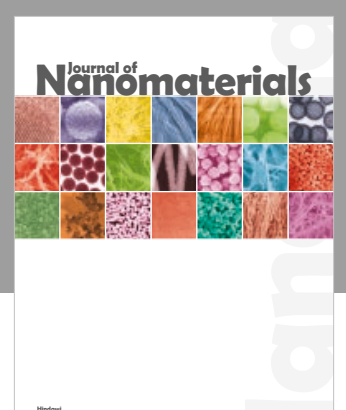

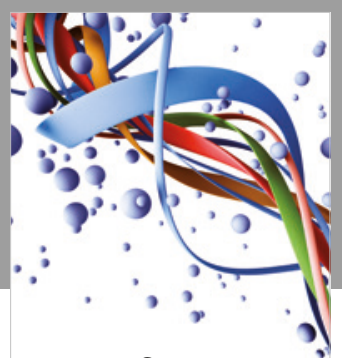

Scientifica

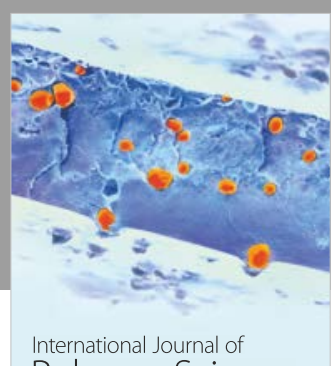

Polymer Science

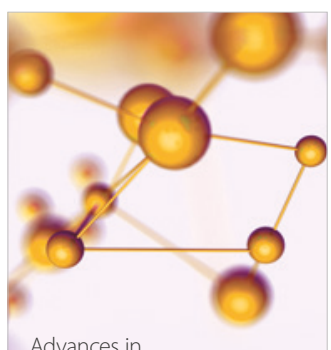

Physical Chemistry
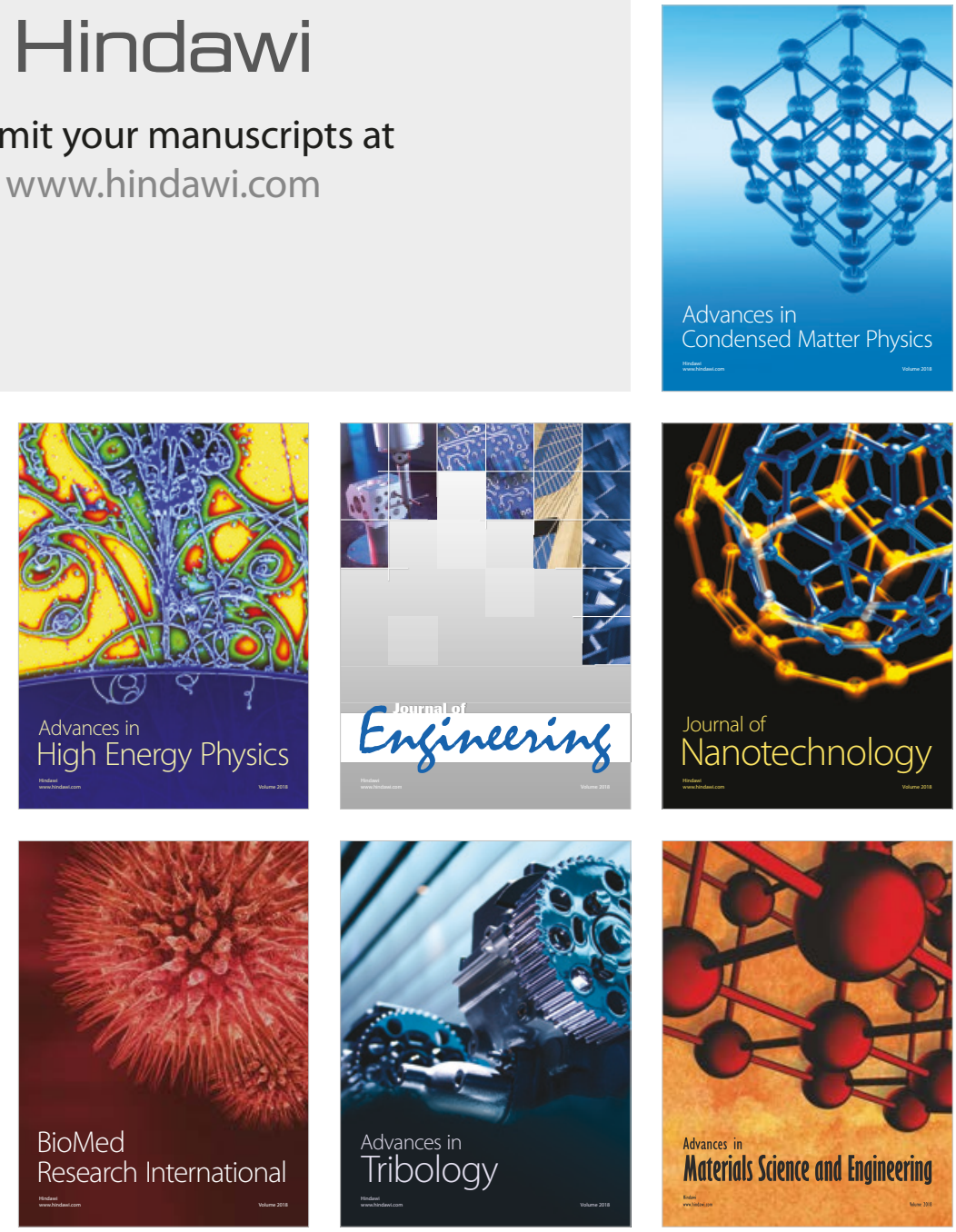